\title{
I. Kampf gegen die Vergangenheit
}

\section{Aus Königsberg wird Kaliningrad}

\section{Kriegsende und Annexion}

„Die Vorboten der Katastrophe machten sich bereits in den letzten Junitagen 1944 bemerkbar - leichte, kaum ins Bewußtsein dringende Stöße, die das sonnendurchglühte Land wie von fernem Erdbeben erzittern ließen." Die Katastrophe, an die sich der Arzt Hans Graf von Lehndorff im Jahre 1947 wie an ein Natureignis erinnerte, das Ostpreußen buchstäblich aus heiterem Himmel ereilte, war die Endphase des Zweiten Weltkrieges". Für die Menschen auf der anderen Seite der Front hatte diese „Katastrophe“ früher begonnen - dementsprechend unterschiedlich war ihre Perspektive auf die letzten Monate des von Stalin so bezeichneten „Großen Vaterländischen Krieges“. Etwas mehr als drei Jahre waren seit dem deutschen Überfall auf die Sowjetunion am 22. Juni 1941 vergangen; nun erreichte die Rote Armee im Herbst 1944 die deutsch-sowjetische Grenze von 1939 und näherte sich Königsberg, der östlichsten deutschen Großstadt. In einem Aufruf des Kriegsrates der 3. Weißrussischen Front, den die Militärzeitung Krasnoarmejskaja Pravda am 16. Oktober 1944, dem ersten Tag der sogenannten „Ostpreußischen Operation“ der Roten Armee, veröffentlichte, appellierte die Armeeführung an die Rache- und Vergeltungsgefühle vieler sowjetischer Soldaten: „Merke Dir, Soldat! Dort in Deutschland versteckt sich der Deutsche, der Dein Kind gemordet, Deine Frau, Braut, Schwester vergewaltigt, Deine Mutter, Deinen Vater erschossen, Deinen Herd niedergebrannt hat. Geh mit unauslöschlichem Haß gegen den Feind vor! Deine heilige Pflicht ist es [...], in die Höhle der Bestie zu gehen und die faschistischen Verbrecher zu bestrafen." 2

Binnen einer Woche gelang es der 11. Gardearmee, die deutschen Verteidigungslinien $\mathrm{zu}$ durchbrechen und einen bis $\mathrm{zu} 40$ Kilometer tiefen Angriffskeil nach Ostpreußen hineinzutreiben. In Moskau ließ Stalin am 23. Oktober aus Freude über die sowjetischen Erfolge zu Ehren der 3. Weißrussischen Front einen Salut von 20 Artilleriesalven aus $224 \mathrm{Ge}-$ schützen abfeuern. Die Offensive der Roten Armee in Ostpreußen blieb je-

1 Lehndorff, Ostpreußisches Tagebuch, S. 9.

2 Zitiert nach: Zeidler, Kriegsende im Osten, S. 70 f. 
doch nach den anfänglichen Erfolgen an ebendiesem Tag stecken, da es den Truppen der 1. Baltischen Front nicht gelang, die nördliche Flanke dieser Offensive zu decken. Angesichts eines drohenden Zangenangriffes deutscher Einheiten auf die ungeschützten Flanken der 11. Gardearmee entschloß sich der Frontoberbefehlshaber Ivan D. Černjachovskij am 23. Oktober, diese aus den bereits eroberten Gebieten westlich des Flusses Romite zurückzuziehen.

In den von der Roten Armee aufgegebenen Ortschaften fanden die nachrückenden deutschen Soldaten die Leichen von 65 ermordeten Zivilisten. Die Toten von Nemmersdorf und den anderen kleinen Gemeinden und Städten der zeitweilig zurückeroberten Gebiete waren nach amtlichen deutschen Untersuchungen zumeist aus nächster Nähe erschossen worden. Die Leichen wiesen Verwundungen auf, die - so der Bericht - eine „z.T. bestialische Ermordung erkennen ließen"3, viele Frauen waren zudem vor ihrem Tod vergewaltigt worden. Die NS-Propaganda versuchte, diese Kriegsverbrechen der Roten Armee in die Ideologie vom asiatischen „Untermenschen" einzuordnen und sie zu instrumentalisieren, um den Durchhaltewillen der Bevölkerung im Osten zu stärken; die Meldungen hatte jedoch den gegenteiligen Effekt: Die Berichte über die Morde ließen der deutschen Bevölkerung nicht nur „das Blut erstarren“4, sondern trieben sie - entgegen den Anweisungen der deutschen Behörden - massenhaft zur Flucht ${ }^{5}$. Damit begann eine erste gewaltige Fluchtbewegung aus dem Osten Deutschlands. Der Flüchtlingsstrom ebbte allerdings schnell ab, als die Front wieder zum Stehen kam und „eine fast unbegreifliche Ruhe“ einkehrte ${ }^{6}$.

Mit dieser Ruhe war es im Januar 1945 jedoch endgültig vorbei. Nach einer mehrmonatigen Pause begann am 13. Januar die 3. Weißrussische Front mit ihrer zweiten Offensive gegen Ostpreußen, die nach den Worten des Historikers Manfred Zeidler Bestandteil der "gewaltigsten Offensivoperation des Zweiten Weltkrieges" war, bei der die Rote Armee von der Ostsee bis in die Ukraine gleichzeitig zum Angriff überging und allein in Polen auf einer Breite von 250 Kilometern die deutsche Front durchbrach? Innerhalb weniger Tage eroberten die sowjetischen Truppen weite Teile Ostpreußens und kesselten die deutschen Truppen im Samland, in Königs-

3 Zitiert nach: Zeidler, Kriegsende im Osten, S. 74.

4 Lehndorff, Ostpreußisches Tagebuch, S. 10.

5 Zum Verlauf der sowjetischen Offensive in Ostpreußen im Oktober 1944 vgl.: Zeidler, Kriegsende im Osten, S. 67-75. In einer neueren russischen Veröffentlichung zur Geschichte Ostpreußens wird weiterhin abgestritten, daß die Toten von Nemmersdorf Opfer sowjetischer Kriegsverbrechen geworden seien. Es handele sich hier überwiegend um Zivilisten, die zwischen die Fronten geraten seien; die „Nemmersdorfer Fälschungen“ seien längst widerlegt. Vgl. Isupov (Hg.), Vostočnaja Prussija, S. 422-424. Die jüngste Darstellung eines deutschen Historikers zu diesem Thema: Fisch, Nemmersdorf, Oktober 1944.

6 Lehndorff, Ostpreußisches Tagebuch, S. 10.

7 Zeidler, Kriegsende im Osten, S. 83. 
berg und Heiligenbeil ein. Nachdem der in den ersten Tagen der sowjetischen Offensive zähe Widerstand der Wehrmacht gebrochen war, setzte in der Bevölkerung Ostpreußens eine weitgehend ungeordnete und überstürzte Fluchtbewegung ein, die diejenige vom Herbst des vorhergehenden Jahres in ihrem Umfang bei weitem übertraf. In langen Trecks machten sich fast alle Einwohner Ostpreußens mitten im Winter auf den Weg nach Westen. Eine traurige Berühmtheit erlangten dabei die vielen Flüchtlinge, die beim Versuch, über das zugefrorene Frische Haff zum Hafen Pillau zu gelangen, um von dort mit Schiffen über die Ostsee $z u$ flüchten, auf der weiten Eisfläche durch Angriffe sowjetischer Tiefflieger getötet wurden. Bei Temperaturen weit unter dem Gefrierpunkt endete die Flucht zudem für viele Flüchtlinge auch ohne die direkte Einwirkung der Roten Armee tödlich ${ }^{8}$.

Königsberg, dessen Zentrum in den letzten Augusttagen des Jahres 1944 in zwei Nachtangriffen der Royal Air Force bereits weitgehend zerstört worden war, wurde am 26. Januar 1945 zum ersten Mal von der sowjetischen Artillerie beschossen. Fünf Tage vorher war der letzte Zug mit Flüchtlingen aus der Stadt abgefahren, seitdem war auch Königsberg eingekesselt. In der Stadt befanden sich neben mehreren zehntausend Königsbergern und Flüchtlingen, die es nicht nicht mehr geschafft hatten, bis in das rettende Pillau zu kommen, verschiedene Truppenteile der Wehrmacht und mehrere Bataillone des „Volkssturmes“. Der berüchtigte Gauleiter von Ostpreußen, Erich Koch, hatte sich hingegen auf den Fliegerhorst Neutief auf der Frischen Nehrung gegenüber von Pillau zurückgezogen, von wo aus er Hitler in Telegrammen suggeriert haben soll, daß er sich noch im eingeschlossenen Königsberg befinde9. Mitte Februar gelang es der Samlandgruppe der Wehrmacht, durch eine überraschende Gegenoffensive eine der vier angreifenden sowjetischen Armeen zurückzudrängen und auf diese Weise für kurze Zeit einen Korridor zwischen Königsberg und Pillau zu schaffen. Durch ihn gelangten noch einmal einige tausend Flüchtlinge nach Pillau, bis die Rote Armee dieses Gebiet wieder zurückeroberte. Der Kommandant der nun endgültig eingeschlossenen „Festung Königsberg“, General Otto Lasch, rief seine Soldaten wenige Tage später in einem Tagesbefehl angesichts der hoffnungslosen Lage auf, zu kämpfen, „wie es das Vaterland von uns verlangt; dann haben wir die Gewißheit, daß wir etwas erkämpfen, wenn nicht unser Leben, so doch unsere Ehre"10.

8 Vgl. Dokumentation der Vertreibung der Deutschen, Bd I., und die von Henke, Exodus aus Ostpreußen, S. 117-127 zitierten Erlebnisberichte. Diese stammen aus der Ost-Dokumentation des Bundesarchivs, die die Grundlage für die „Dokumentation der Vertreibung der Deutschen" bildet, sind in dieser aber nicht enthalten.

9 Vgl. Gause, Geschichte der Stadt Königsberg, Bd. III, S. 162.

10 Zitiert nach: Süßkind-Schwendi, Kurze Rückschau auf die militärischen Ereignisse, S. 222. 
Der März verlief in Königsberg verhältnismäßig ruhig, da der neue Befehlshaber der 3. Weißrussischen Front, Marschall Aleksandr M. Vasilevskij, nach der empfindlichen Schlappe im Februar zunächst alle sowjetischen Truppen für die Bekämpfung des Heiligenbeiler Kessels einsetzte. Erst nach dessen "Liquidierung" forcierte Vasilevskij die Vorbereitungen für die Erstürmung Königsbergs. Dort wurde derweil - wie bereits in einigen anderen eingeschlossenen deutschen Städten - der Durchhaltefilm „Kolberg" gezeigt" ${ }^{11}$. Am 6. April 1945 begann der entscheidende und schließlich erfolgreiche Angriff der sowjetischen Roten Armee auf Königsberg, für den insgesamt über 150000 Soldaten zusammengezogen worden waren. Die von Hitler befohlene sinnlose Verteidigung der Stadt wurde bereits am zweiten Tage der sowjetischen Offensive vollends selbstmörderisch, da die deutschen Verteidiger zu diesem Zeitpunkt kaum noch Munition besaßen ${ }^{12}$. Trotzdem kapitulierte General Otto Lasch erst am Abend des 9. April 1945. Nur einen Monat vor der Gesamtkapitulation Deutschlands - und zu einem Zeitpunkt, als General Bersarin bereits den Angriff auf Berlin vorbereitete - übergab Lasch den Vertretern Vasilevskijs die Reste seiner „Festung Königsberg“. Diese war nach dem viertägigen Sturmangriff der Roten Armee und einem Häuserkampf, der viele bislang von Bomben und Granaten verschonte Stadtteile dem Erdboden gleichmachte, auf die unmittelbare Umgebung seines Befehlsbunkers zusammengeschmolzen ${ }^{13}$.

Stolz meldete die Pravda zwei Tage nach der Kapitulation von Lasch: „Die deutschen Räuber machten seit jeher aus Königsberg einen Vorposten ihrer Eroberungspolitik im Osten Europas. Die Deutschen haben das Territorium Ostpreußens in eine Aufmarschbasis für Eroberungsüberfälle auf slawisches Gebiet verwandelt. [...] Nun hat die Rote Armee dieses Räubernest des deutschen Imperialismus in Königsberg auf ewig liquidiert."14 Auch Otto Lasch zog - Jahre später - eine positive Bilanz der blutigen Kämpfe um die ostpreußische Hauptstadt, obwohl er aufgrund seiner Kapitulation von Hitler als Deserteur in Abwesenheit zum Tode verurteilt worden und seine Familie in Sippenhaft genommen worden war. Von einem sowjetischen Tribunal wiederum wurde er wegen angeblicher von ihm bestrittener Greueltaten zu 25 Jahren Lagerhaft verurteilt. Nachdem er 1955 als einer der letzten Wehrmachtsangehörigen aus sowjetischer Gefangenschaft zurückkehrte, schrieb er in seinen 1958 erschienenen Erinnerungen: „Aus den zahlreichen Gesamtschilderungen der Kämpfe um die Festung

11 Vgl. Lehndorff, Ostpreußisches Tagebuch, S. 44.

12 Vgl. Süßkind-Schwendi, Kurze Rückschau auf die militärischen Ereignissc, S. 221-227, bes. S. 225.

13 Zum Kriegsende in Königsberg vgl. Lasch, So fiel Königsberg; Wieck, Zeugnis vom Untergang; Gause, Königsberg, Bd. III., S. 156-170; Zeidler, Kriegsende im Osten, S. 86-93. Aus sowjetischer Sicht: Bagramjam, Šturm Kenigsberga. Zum fünfzigsten Jahrestag der Eroberung Königsbergs erschien in Kaliningrad: Dar'jalov, Kenigsberg. Cetyre dnja šturma.

14 Aus: A. Ivanov, Kenigsberg, in: Pravda, 11. 4. 1945. 
Königsberg ergibt sich im übrigen, daß jeder Einzelne in beispielhafter Weise bis zum Ende seine Pflicht getan hat, so daß der Endkampf um die ostpreußische Heimaterde immerdar ein Ruhmesblatt in der Geschichte des deutschen Soldatentums und der ostpreußischen Menschen bleiben wird."15

Der Frieden, der auf den „heroischen Endkampf“ folgte, war schrecklich. Die Zivilisten, die in den Kellern in den Vororthäusern während der Kämpfe ausgeharrt hatten, wurden am 8. April, noch während im Stadtzentrum gekämpft wurde, von Soldaten der Roten Armee aufgefordert, sich an Sammelpunkten einzufinden. Von dort aus wurden sie in langen Kolonnen aus der Stadt heraus und kilometerweit über das Land geführt. Diese „Propagandamärsche", wie sie in den Erinnerungsberichten der Deutschen genannt werden, führten zu keinem für die Betroffenen erkennbaren Ziel und endeten nicht selten wieder in der Nähe von Königsberg. In der Stadt selbst wurden derweil viele Gebäude in Brand gesteckt, auch in Vierteln, die die Rote Armee bereits fest in ihrer Hand hatte. Sowjetische Soldaten zogen plündernd durch die Stadt, und es kam zu zahlreichen Vergewaltigungen ${ }^{16}$.

Den deutschen Erinnerungsberichten und Tagebüchern ist zuweilen anzumerken, daß die Königsberger in den Gewalttaten der sowjetischen Soldaten während und nach der Erstürmung Königsbergs die Erfüllung der NS-Propaganda sahen. So schrieb z. B der Arzt Hans Deichelmann in seinem Tagebuch am 20. April 1945 im Zusammenhang mit den Vergewaltigungen durch sowjetische Soldaten von der „viehischen Brutalität der Asiaten"17. Es dauerte Tage, bis die gewaltsamen Ausschreitungen gegen die Zivilbevölkerung eingedämmt wurden, so lange war sie laut zahlreichen Augenzeugenberichten der Willkür der Rotarmisten schutzlos ausgeliefert. In der Kaserne Rothenstein am nördlichen Stadtrand von Königsberg wurde zudem kurze Zeit nach der Besetzung der Stadt durch die sowjetischen Truppen vom NKVD (Narodnyj Kommisariat Vnutrennich DelVolkskommissariat für innere Angelegenheiten) ein Internierungslager für politisch verdächtige Deutsche eingerichtet, aus denen die NSDAP-Mitglieder herausgefiltert werden sollten, in dem aber auch eine große Anzahl ohne Anschuldigung Verhafteter über Wochen hin festgehalten wurde ${ }^{18}$. Wie ernst die sowjetischen Militärs nach der Besetzung Königsbergs die tatsäch-

15 Lasch, So fiel Königsberg, zitiert nach: Wieck, Zeugnis vom Untergang, S. 220.

16 Vgl. Wieck, Zeugnis vom Untergang, S. 224-232, und Gause, Königsberg, S. 170-172.

17 Deichelmann, Ich sah Königsberg sterben, S. 25. Dieser Ausdruck wurde von vielen Deutschen durchaus wörtlich im Sinne einer besonders hohen Beteiligung von „asiatischen“ Rotarmisten bei den Ausschreitungen aufgefaßt, was aber selbst die deutsche militärische Aufklärung nach den Nemmersdorfern Vorfällen in Zweifel zog. Vgl. dazu und zu dem gesamten Komplex des Verhaltens der sowjetischen Soldaten gegenüber der deutschen Bevölkerung: Zeidler, Kriegsende im Osten, S. 143-154.

$18 \mathrm{Vgl}$. Wieck, Zeugnis vom Untergang, S. 244-255, und Lehndorff, Ostpreußisches Tagebuch, S. 104-137. Zu den Ausschreitungen nach der Eroberung Königsbergs durch die Rote Armee vgl. insbesondere: Dokumentation der Vertreibung, Bd I,1. 
lich nicht existente Bedrohung durch Werwölfe und untergetauchte SSMänner nahmen, wird aus einer Anordnung des Militärkommandanten von Königsberg vom 1. Mai 1945 deutlich. Darin warnte er seine Untergebenen - noch ganz im Tonfall der hochstalinistischen Spionagephobie der Vorkriegsjahre - vor der Heimtücke des niedergerungenen Feindes: „Die das Land verwüstenden Schlachten der Schergen Hitlers spielen sich jetzt im Untergrund $a b$, und es halten sich Spione, Diversanten und terroristische Gruppen für Sprengarbeiten bereit. Die Gruppen rechtzeitig zu entlarven und unschädlich zu machen, gelingt nur dann, wenn jeder Soldat und Offizier wach und diszipliniert die ihm übertragenen Aufgaben erfüllt."19 Auch die ersten Maßnahmen, mit denen die neuen Machthaber das Stadtbild veränderten, dienten der Absicherung gegen die trotz ihrer totalen Niederlage im totalen Krieg als permanente Bedrohung empfundenen Deutschen. Binnen kurzer Zeit wuchsen in der Stadt „eigenartige Holzzäune“ empor ${ }^{20}$, die zuweilen ganze Straßenzüge für den allgemeinen Durchgang absperrten, und an den Kreuzungen erhoben sich Wachtürme, so als sei die ganze Stadt ein einziges Lager ${ }^{21}$.

Mit der Eroberung Königsbergs durch die Rote Armee begann das letzte Kapitel der deutschen Geschichte der Stadt, deren Ende freilich bereits seit einiger Zeit feststand. Schon Ende 1943 hatte Stalin auf der Konferenz der Anti-Hitler-Koalition in Teheran den Anspruch der Sowjetunion auf die eisfreien Häfen Königsberg und Memel „sowie einen entsprechenden Teil des ostpreußischen Territoriums" angemeldet und dies mit dem Hinweis untermauert, daß Ostpreußen „historisch gesehen slawischer Boden ist“22. Ohne diesen Anspruch mit den westlichen Alliierten endgültig geklärt zu haben, arbeitete die sowjetische Diplomatie im Sommer 1944 auf eine Aufteilung Ostpreußens zwischen Polen und der Sowjetunion hin: In einem Vertrag zwischen der UdSSR und dem Polnischen Komitee der Nationalen Befreiung vom 27. Juli 1944 heißt es in Artikel 2, beide Parteien seien der Ansicht, daß die UdSSR den nördlichen Teil des ostpreußischen Territoriums mit der Stadt Königsberg, und Polen den südlichen Teil nebst dem ehemaligen Danziger Gebiet erhalten solle ${ }^{23}$. Nachdem das U.S. State Department in einem Memorandum vom 12. Januar 1945, das für die Konferenz von Jalta erarbeitet worden war, die Übertragung des nördlichen Ostpreußen an die Sowjetunion nicht mehr ausschloß ${ }^{24}$, konnte sich Stalin mit seinem Annexionswunsch auf der Potsdamer Konferenz im Juli und August

19 Zitiert nach: Matthes, Als Russe in Ostpreußen, S. $312 \mathrm{f}$.

20 Wieck, Zeugnis vom Untergang, S. 273.

21 Falk, Ich blieb in Königsberg, S. 118.

22 Protokoll der vierten Sitzung der Regierungschefs in Teheran am 1. Dezember 1943. II. Sitzung am Runden Tisch, in: Teheran. Jalta. Potsdam, S. 138.

23 Vgl. Wörster, Ostpreußen nach 1945, S. 9. Zu den Verhandlungen zwischen Stalin und der Kommission der PKWN vgl. Zeidler, Kriegsende im Osten, S. 56-59.

24 State Department, The Conferences of Malta and Yalta, S. 188-190, 232-234. 
1945 endgültig durchsetzen. Im Potsdamer Abkommen wurde schließlich festgestellt: „Die Konferenz hat grundsätzlich dem Vorschlag der Sowjetregierung hinsichtlich einer Übergabe der Stadt Königsberg und des anliegenden Gebietes an die Sowjetunion [...] zugestimmt, wobei der genaue Grenzverlauf einer sachverständigen Prüfung bedarf." 25

In Königsberg waren derweil Fakten geschaffen worden. Bereits am 7. April 1945, als der Belagerungsring um Königsberg zwar schon geschlossen war, im Stadtzentrum jedoch noch verlustreiche Häuserkämpfe stattfanden, wurde die sowjetische „Militärkommandantur der Stadt und Festung Königsberg" gegründet, an deren Aufbau seit Ende März gearbeitet worden war ${ }^{26}$ und die zunächst von Generalmajor Michail V. Smirnov und ab dem 5. Juli 1945 von Gardegeneralmajor Michail A. Pronin geführt wurde27. Dem Militärkommandanten unterstanden neun Offiziere, die u.a. für die Bereiche Kontrolle und Registrierung der deutschen Bevölkerung und Wirtschaft zuständig waren ${ }^{28}$. Die zentrale Militärkommandantur gab Weisungen an die einzelnen Bezirkskommandanturen heraus, von denen in Königsberg zunächst acht (später sechs) eingerichtet wurden. Dort unterstanden dem Bezirkskommandanten drei wachhabende Offiziere und ein Offizier für Wirtschaftsfragen, dem in der ersten Zeit hauptsächlich die Nahrungsmittelbeschaffung für die „örtliche Bevölkerung“ oblag. In jeder Bezirkskommandantur wurde zudem noch eine Paßstelle eingerichtet, die neben der Erfassung von Personen auch die Einteilung von Arbeitskräften übernahm ${ }^{29}$.

Innerhalb der zentralen Kommandantur wurde am 10. Mai 1945 eine „Provisorische Verwaltung für Zivilangelegenheiten“ (Vremenoe upravlenie po graždanskim delam) eingerichtet, der der Stellvertreter des Militärkommandanten vorstand ${ }^{30}$. Da sich zu dieser Zeit überwiegend deutsche Zivilpersonen in Königsberg aufhielten, war die provisorische Verwaltung für Zivilangelegenheiten in den ersten Monaten nach der Eroberung Königsbergs faktisch eine Verwaltung für die deutsche Bevölkerung ${ }^{31}$. Selbstverwaltungsorgane der deutschen Bevölkerung entstanden nicht, da die sowjetischen Behörden bereits davon ausgingen, daß Ostpreußen an die Sowjetunion fallen werde. Stalin machte den sowjetischen Standpunkt in dieser

25 Aus Artikel VI der Mitteilung über die Dreimächte-Konferenz von Berlin vom 2. August 1945 [Potsdamer Abkommen], zitiert nach: Bittel, Das Potsdamer Abkommen; vgl. dazu: Hillgruber, Der Zweite Weltkrieg. 1939-1945, S. 270-342, bes. S. 337 f. Zur sowjetischen Deutschlandplanung im Zweiten Weltkrieg vgl. Filitov, Die sowjetische Deutschlandplanung, S. 117-139.

26 Isupov, Vostočnaja Prussija S. 440.

27 Fisch, Schicksal der Deutschen, S. 392.

28 Isupov, Vostočnaja Prussija, S. 441.

29 Vgl. Luschnat, Lage der Deutschen, S. 60, und Zeidler, Kriegsende im Osten, S. 168-177.

30 Vgl. Isupov, Vostočnaja Prussija, S. 449.

31 Hinweise auf die „Displaced Persons“ fehlen in den sowjetischen Akten weitgehend. 
Angelegenheit wenige Monate später auf der Potsdamer Konferenz noch einmal deutlich, als er gegenüber den Regierungschefs der Westallierten versicherte: „Falls in Königsberg eine deutsche Verwaltung entstehen wird, werden wir sie vertreiben, unbedingt vertreiben." 32 Aus den Reihen der Deutschen wurden daher lediglich sogenannte "Burgomejstera“ ernannt, die als Bindeglied zwischen den Deutschen und den sowjetischen Stellen fungierten. Sie trugen eine Armbinde mit der Aufschrift „Starosta“ (Älteste) und sollten die Ausführung der sowjetischen Weisungen sicherstellen. Bis zum September 1945 wurden in Königsberg 43 „Bürgermeister“ ernannt. Sie waren jeweils für einige Straßenzüge verantwortlich und mußten Listen von den dort wohnenden Deutschen und deren Arbeitsfähigkeit führen ${ }^{33}$. Auf diese Weise sollte in erster Linie die Überwachung der deutschen Bevölkerung garantiert werden, die als ein hohes Sicherheitsrisiko betrachtet wurde. Um so beunruhigender mußte es für die Militärverwaltung sein, daß trotz mehrmaliger Registrierungskampagnen und obwohl ohne Registrierung keine Lebensmittel ausgegeben wurden, es einige Zeit dauerte, bis alle Deutschen durch die sowjetischen Behörden erfaßt worden waren ${ }^{34}$.

Mit der Gründung des Sondermilitärkreises Königsberg (Kenigsbergskij Osobyj Voennyj Okrug) am 9. Juli 1945 wurden die Militärkommandanturen von ihren zivilen Aufgaben in der Verwaltung und Wirtschaft des Gebietes befreit. Die provisorische Verwaltung für Zivilangelegenheiten unterstand von nun an direkt dem Militärrat des neugebildeten Sondermilitärkreises, der für die nächsten Monate die oberste Entscheidungsinstanz im Gebiet darstellte ${ }^{35}$. Die Chefs der jetzt formal selbständigen provisorischen Zentral- und Bezirksverwaltungen blieben zwar immer noch Militärangehörige, doch hießen sie nun „Vorgesetzte der Verwaltung für Zivilangelegenheiten" (Načal'niki upravlenija po graždanskim delam). Diese Militärs bildeten auch nach der Gründung des Königsberger/Kaliningrader Gebietes den Kern der zivilen Verwaltung und der Parteiorganisation des Gebietes ${ }^{36}$. Die Aufgabe der umgebildeten Verwaltung bestand darin, mit dem wirtschaftlichen Aufbau des Gebietes und der regulären Verwaltungsarbeit zu beginnen. Neuer Chef der provisorischen Verwaltung für Zivilangelegenheiten wurde der Generalmajor und Mitglied des Militärrates des Sondermilitärkreises, V. G. Guzii, dem 134 Mitarbeiter in 15 Abteilungen unterstanden ${ }^{37}$.

32 Vgl. Protokoll der zweiten Sitzung der Regierungschefs vom 18. Juli 1945, in: Sovetskij Sojuz na meždunarodnich konferencijach, Bd. 6, S. 61 .

33 GAKO, f. 298, op. 1, d. 21, 1. 181.

34 Vgl. Fisch, Schicksal der Deutschen, S. 394.

35 Vgl. Isupov, Vostočnaja Prussija, S. 449f.

36 Vgl. Luschnat, Lage der Deutschen, S. 62, und Istorija Kraja, S. 51.

37 Vgl. Isupov, Vostočnaja Prussija, S. 450. 
Nachdem am 17. Oktober 1945 das nördliche Ostpreußen von der Sowjetunion offiziell annektiert worden war, wurde es per Erlaß des Ministerrates der UdSSR vom 7. April 1946 als „Königsberger Gebiet“ in die RSFSR eingegliedert ${ }^{38}$. Die provisorische Verwaltung für Zivilangelegenheiten wurde im Zuge dieser Eingliederung durch eine ständige Zivilverwaltung ersetzt, die dem in der Sowjetunion üblichen Aufbau in Gebiets-, Stadt- und Rayonsverwaltung entsprach ${ }^{39}$. Nur wenige Monate später, am 4. Juli 1946, wurde Königsberg in Kaliningrad umbenannt, zu Ehren von Michail I. Kalinin, dem kurz zuvor verstorbenen Präsidenten der UdSSR. Die Umbenennungskampagne für die übrigen Städte und Ortschaften des Gebietes und die Straßen und Plätze fand dagegen erst im Herbst 1947 statt. Vorher waren lediglich diejenigen Straßen und Plätze umbenannt worden, die - wie es in dem entsprechenden Befehl des Militärrates des Sondermilitärkreises vom 23. November 1945 hieß - noch die „Namen faschistischer Banditen, ihrer Anführer und volksfeindlichen Taten" trugen ${ }^{40}$. Selbst in diesen Fällen wurden jedoch zunächst bemerkenswerterweise keine neuen russischen $\mathrm{Be}$ zeichnungen gewählt, sondern die Namen aus der Zeit vor 1933 verwendet - so wurde die General-Litzmann-Straße zunächst wieder in StresemannStraße umbenannt ${ }^{41}$.

Der Übergang zum regulären sowjetischen Staatsaufbau wurde im Frühjahr 1947 vollzogen: Per Erlaß des Präsidiums des Obersten Sowjets der UdSSR vom 28. Mai 1947 entstanden das Kaliningrader Gebietsexekutivkommitee und die untergeordneten Stadt- und Rayonsexekutivkomitees, die die Wahlen zu den örtlichen Räten vorbereiten sollten. Mit ihrer Einsetzung wurde die Verwaltung für Zivilangelegenheiten abgeschafft ${ }^{42}$. Bei der Aufstellung der ersten Exekutivkomitees standen die Behörden allerdings vor dem großen Problem, daß nicht genug Kandidaten aufzutreiben waren. Das ZK der VKP(b) sah sich deshalb gezwungen, zur Unterstützung des Verwaltungsaufbaus „128 erfahrene sowjetische Arbeiter“ in das Gebiet zu delegieren und auch weiterhin auf die leitenden Mitarbeiter der gerade auf-

38 Isupov, Samaja zapadnaja, Dokument No. 1, S. 17.

39 Vgl. Istorija Kraja, S. 51. Michael Wieck, ein in Königsberg gebliebener Deutscher, berichtet in seinen Erinnerungen an die Nachkriegsjahre in der Stadt, daß es bei dieser Verwaltungsumstellung zu ernsthaften Problemen gekommen sei: So habe zwischen der Auflösung der vom Militär gestellten provisorischen Verwaltung und dem Beginn der Arbeit der neuen Zivilverwaltung eine Art Interregnum geherrscht. Infolgedessen habe die Rote Armee mehrere Wochen lang ihre Lebensmittellieferungen für das Gebiet eingestellt. Vgl. Wieck, Zeugnis vom Untergang, S. 302.

40 Verordnung des Militärrates des Besonderen Militärkreises Königsberg vom 23. November 1945, zitiert nach: Pavlovskij, Semlja moja, S. 36.

41 Vgl. Kalusche, Sowjetstern, S. 75. Der Arzt Hans Deichelmann schrieb zudem am 16. August 1946 in sein Tagebuch, daß in Kaliningrad die russischen Wegweiser wieder durch deutschsprachige ersetzt worden seien. Vgl: Deichelmann, Ich sah Königsberg sterben, S. 118. Zur Umbenennungskampagne in den Städten und Dörfern des Gebietes vgl. Krivorucka, Kampanija pereimenovanij, S. 90-106.

42 Isupov, Samaja zapadnaja, No. 10, S. 21. 
gelösten Verwaltung für Zivilangelegenheiten zurückzugreifen ${ }^{43}$. Erst Ende Oktober 1947 war der Aufbau des Gebietsexekutivkomitees abgeschlossen, so daß am 21. Dezember 1947 zum ersten Mal die örtlichen Deputierten gewählt werden konnten ${ }^{44}$. Diese Wahlen wurden von vielen als ein „eine Rückkehr zu einem friedlichen Leben“ gesehen, mit ihnen waren „Hoffnungen auf eine bessere Zeit verbunden", wie sich eine sowjetische Umsiedlerin später erinnerte: „Bis dahin gab es nur eine Zivilverwaltung, und die Leute waren mit vielem dort nicht einverstanden." 45

Auch die Bildung der örtlichen und regionalen Parteigliederungen verzögerte sich. Erst am 7. März 1947 - also fast zwei Jahre nach der Eroberung Königsbergs - wurde das Gebietskomitee der VKP(b) gegründet. Wieder mußte das Moskauer ZK den Kaliningradern unter die Arme greifen, um den schwachen Personalbestand aufzustocken und somit eine effektive Arbeit überhaupt erst zu ermöglichen. Im Laufe des Jahres 1947 wurden insgesamt 575 Parteifunktionäre in das Kaliningrader Gebiet entsandt; Anfang Dezember 1947 konnte schließlich die erste Gebietsparteikonferenz stattfinden. Zu diesem Zeitpunkt hatte der erste Gebietsparteivorsitzende, Jurij P. Ivanov, bereits vor den Problemen des Wiederaufbaus kapituliert ${ }^{46}$, und sein Nachfolger Vladimir Ščerbakov bemühte sich, die Funktionäre für ihre Arbeit zu begeistern ${ }^{47}$.

\section{Besiedlung und Vertreibung}

Abgesehen von der formellen Sowjetisierung des nördlichen Ostpreußen durch dessen staatliche und verwaltungstechnische Eingliederung in die UdSSR stellten sich den sowjetischen Behörden seit dem 9. April 1945 zwei wesentliche Aufgaben: Zum einen war die verbliebene deutsche Bevölkerung zu kontrollieren und zu versorgen, zum anderen sollte das wirtschaftliche Potential des Gebietes genutzt und die Region mit sowjetischen Bürgern besiedelt werden ${ }^{48}$. Wie eng diese beiden Aufgaben miteinander verbunden waren, zeigt die Schwierigkeit, die Ursachen für das bis 1947 geltende Ausreiseverbot für die deutsche Bevölkerung und deren seit Oktober 1947 erfolgte schrittweise Aussiedlung ${ }^{49}$ herauszuarbeiten. Obwohl der Aufbau einer eigenständigen deutschen Verwaltung aus den oben genannten

43 Istorija Kraja, S. 53.

44 Ebenda, S. 59 f.

45 Matthes, Russe in Ostpreußen, S. 226.

46 Nach Ausagen mehrerer Zeitzeugen hat er sich erschossen, angeblich nach einem Telefonat mit Stalin. Vgl. Matthes, Als Russe in Ostpreußen, S. 227.

47 Vgl. dessen Rede vor der ersten Gebietsparteikonferenz im Jahre 1947: Ščerbakov, Stalinskaja Programma.

48 Die offenkundige militärische Bedeutung des Kaliningrader Gebietes für die Sowjetunion bleibt in diesem Zusammenhang unberücksichtigt.

49 Vgl. Kostjašov, Vyselenie nemcev iz Kaliningradskoj oblasti, S. 187. 
Gründen nie in Erwägung gezogen wurde, stand die spätere Aussiedlung der Deutschen offensichtlich keineswegs schon 1945 fest $^{50}$. So zeigte sich beispielsweise noch wenige Monate vor dem Aussiedlungsbeschluß vom Oktober 1947 ein Offizier des Geheimdienstes nach Angaben des in Kaliningrad gebliebenen Pfarrers Hugo Linck ihm gegenüber betroffen, als der Geistliche ihm mitteilte, daß alle Deutschen aufgrund der schlechten Lebensbedingungen aus dem nördlichen Ostpreußen nach Deutschland ausreisen wollten. Diese Reaktion des Geheimdienstmannes ist nur verständlich, wenn der Offizier davon ausging, daß die deutsche Bevölkerung weiter in Kaliningrad bleiben sollte. Als Linck seine Gemeindemitglieder zudem ermunterte, Ausreiseanträge zu stellen, waren die sowjetischen Behörden von der daraufhin einsetzenden Flut der Anträge völlig überrascht ${ }^{51}$. Auch in anderen Städten des Kaliningrader Gebietes kam die Antragswelle der Ausreisewilligen unerwartet, wie eine Heimatvertriebene aus Tapiau berichtete: „Die Russen mögen gedacht haben, vielleicht wollen nur fünf Leute aus Tapiau fort, aber wie staunten sie, als restlos alle Deutschen das Paradies verlassen wollten, sogar unsere Kommunisten konnten dem Land ihrer Sehnsucht nicht schnell genug den Rücken kehren. "52 Somit herrschte nicht nur unter den Deutschen selbst bis zu ihrer endgültigen Ausweisung eine große Unsicherheit über die sie betreffenden Pläne der sowjetischen Führung. Auch die örtlichen sowjetischen Behörden wußten nicht, ob die Deutschen schließlich in die Sowjetunion eingebürgert oder ausgesiedelt werden sollten, sobald ihre Arbeitskraft nicht mehr benötigt würde. Der raschen Annexion folgte in dieser Hinsicht eine Phase der Stagnation, und die ehemalige Hauptstadt Ostpreußens erlebte eine Zeit der Zwitterexistenz: Kaliningrad war keine deutsche Stadt mehr, aber noch längst keine sowjetische.

In der unmittelbaren Nachkriegszeit stellte sich die Alternative Einbürgerung oder Ausweisung jedoch zunächst gar nicht, da die Deutschen als Arbeitskräfte für den Wiederaufbau dringend benötigt wurden, solange kaum sowjetische Bürger zur Verfügung standen. In den ersten Tagen nach der

50 Möglicherweise waren die sowjetischen Behörden auch von der Tatsache überrascht, überhaupt noch in nennenswertem Umfang deutsche Zivilisten in dem Gebiet vorzufinden. Stalin sprach auf den Konferenzen von Jalta und Potsdam mehrmals davon, daß es in den von der Roten Armee besetzten Gebieten kaum noch deutsche Zivilisten gebe, da diese mit den Verbänden der Wehrmacht nach Westen geflohen seien. Vgl. Zeidler, Kriegsende im Osten, S. 65.

51 Linck, Königsberg 1945-1948, S. 129. Vgl. dazu auch: Kostjašov, Vyselenie nemcev iz Kaliningradskoj oblasti, S. 187, der ebenfalls betont, daß er den Eindruck gewonnen habe, daß die Aussiedlung der Deutschen aus dem Kaliningrader Gebiet „anfangs gar nicht von der sowjetischen Führung beabsichtigt war". Seinen Angaben zufolge wurde bis zum Beginn der Aussiedlung im Jahre 1947 nur etwa 3400 Deutschen die Ausreise nach Deutschland gestattet. Die meisten seien Mitglieder antifaschistischer Organisationen gewesen oder konnten Angehörige in Deutschland nachweisen.

52 BMfV, Dokumentation, Bd. II, S. 857. 
Kapitulation von Otto Lasch wurden die deutschen Zivilisten vor allem für die Bergung der Leichen und die Freiräumung der Straßen unter der Aufsicht von sowjetischen Soldaten eingesetzt. Um die Arbeitskraft der verbliebenen Deutschen besser nutzen zu können, wurde von der Militärkommandantur am 26. April 1945 eine Paßstelle in Königsberg eingerichtet ${ }^{53}$, die im Mai 1945 von der Verwaltung für Zivilangelegenheiten übernommen wurde ${ }^{54}$. Die Aufgabe dieser Behörde bestand in der Registrierung der Deutschen und der „Nutzung der deutschen Bevölkerung“ (ispol'zovanie nemeckogo naselenija $)^{55}$. Sie übte also gleichzeitig die Funktion einer Meldebehörde wie auch einer Arbeitsverwaltung aus. Viele Deutsche befürchteten daher zu Recht, gleich im Anschluß an ihre Registrierung zur Arbeit abgeführt zu werden. Dies dürfte eine wesentliche Ursache für die zahlreich belegte Widerwilligkeit der Deutschen, sich registrieren zu lassen, gewesen $\operatorname{sein}^{56}$ - zudem gibt es Berichte, daß die Registrierung häufig mit Verhören und teilweise auch Mißhandlungen verbunden war ${ }^{57}$.

Nach der Erfassung der deutschen Bevölkerung konnten Militäreinheiten, Betriebe und Dienststellen der Verwaltung ihren Arbeitskräftebedarf an die Zentralkommandantur übermitteln, die dies an die Bezirkskommandanten weitergab und die Vergabe von Arbeitskräften veranlaßte. Für den Königsberger siebten Bezirk sind beispielsweise für den Monat Juli 194575 einzelne Militäreinheiten, Betriebe und Dienststellen aufgeführt, die offiziell Deutsche beschäftigten. Ende Mai 1946 waren in ganz Königsberg knapp 19000 zur Arbeit eingeteilte Deutsche bei der Verwaltung für Zivilangelegenheiten gemeldet ${ }^{58}$. Den Arbeitslohn erhielten die Deutschen anfangs jedoch nicht direkt ausgezahlt; dieser mußte von den Arbeitgebern auf das Konto des Militärkommandanten bei der Staatsbank überwiesen werden ${ }^{59}$.

Der Zusammenhang zwischen dem allgemeinen Arbeitskräftebedarf und der Politik gegenüber den Deutschen läßt sich nicht zuletzt daran erkennen, daß der allgemeine Arbeitszwang für die Deutschen erst im Sommer 1946 aufgehoben wurde ${ }^{60}$ : Nach Angaben der Verwaltung für Zivilangelegenhei-

53 Luschnat, Lage der Deutschen, S. 64.

54 Fisch/Klemeševa, Schicksal, S. 392.

55 Isupov, Vostočnaja Prussija, S. 492 f.

56 Eine erste Registrierung der Königsberger „örtlichen Bevölkerung“ erfaßte am 26. April 1946 nur etwa 23000 Personen. Diese Zahl erschien den Behörden viel zu niedrig: Sie schätzten, daß sich allein in Königsberg noch mindestens weitere 40000 Deutsche aufhalten müßten. Vgl. Kostjašov, Vyselenie nemcev iz Kaliningradskoj oblasti, S. 186.

57 Vgl. Luschnat, Lage der Deutschen, S. 63, und Falk, S. 13 f.

58 Vgl. Isupov, Vostočnaja Prussija, S. 493.

59 Vgl. Luschnat, Lage der Deutschen, S. 93. Eine nach Sparten aufgeliederte Tabelle über die Anzahl der am 24. Mai 1946 in Königsberg beschäftigten Deutschen ist abgedruckt in: Isupov, Vostočnaja Prussija, S. 493. Danach waren zu diesem Zeitpunkt etwa 19000 Deutsche zur Arbeit verpflichtet.

60 BMfV, Dokumentation, Bd. II, S. $141 \mathrm{f}$. 
ten näherte sich zu diesem Zeitpunkt die Anzahl der sowjetischen Bürger im Kaliningrader Gebiet der Anzahl der verbliebenen Deutschen an ${ }^{61}$, wodurch sich die Arbeitskräftenachfrage geringfügig entspannte. Die Aufhebung des Arbeitszwanges galt jedoch nicht für Facharbeiter, die ihr Wissen an die sowjetischen Neusiedler weitergeben sollten und die deswegen auch als letzte aus dem Kaliningrader Gebiet ausgesiedelt wurden ${ }^{62}$. Um ihre Arbeitskraft gezielt einzusetzen, wurden sie zudem gesondert registriert: Die Abteilung für Abrechnung und Verteilung von Arbeitskräften bei der Zentralkommandantur hatte eine Personalkartei angelegt, in der die deutschen Fachleute mit Namen und Qualifikation vermerkt waren ${ }^{63}$. Die starke Nachfrage nach Facharbeitern hatte für die deutschen Spezialisten allerdings auch positive Folgen für ihre Lebensumstände. Diese waren ungleich günstiger als diejenigen von Deutschen, die keine oder eine nicht benötigte berufliche Qualifikation hatten: Deutsche Facharbeiter wurden in der sowjetischen Gesellschaft respektiert ${ }^{64}$, zuweilen wurden ihnen leitende Positionen in anderen Gebieten der Sowjetunion angeboten ${ }^{65}$, und einige Arbeitgeber versuchten, die deutschen Facharbeiter zum Bleiben in Königsberg zu bewegen, als die Deutschen Ausreiseanträge stellen durften ${ }^{66}$. Der Arzt Hans Deichelmann vermerkte in seinem Tagebuch, daß die deutschen „Spezialisten“ den einfachen russischen Arbeitern reich erschienen, da diese Fachleute überdurchschnittlich verdienten und somit zu einer den einfachen Russen „ewig unerreichbaren Schicht“ gehörten 67.

Die Lage der Deutschen stellte sich jedoch durchaus widersprüchlich dar: Während einerseits Facharbeiter umworben oder jahrelang festgehalten wurden, weil ihr Wissen unentbehrlich war, haben anderseits deutsche Zeitzeugen berichtet, daß ein halbes Jahr vor der im Herbst 1947 beginnenden Ausweisung der deutschen Bevölkerung eine schrittweise Verdrängung von Deutschen aus dem Arbeitsleben zu beobachten war ${ }^{68}$. In erster Linie betraf dies die unqualifizierten Arbeiterinnen und Arbeiter, doch auch eine gute Berufsausbildung stellte nun keine Garantie mehr für einen Arbeitsplatz dar. Von deutscher Seite her ist dies am besten für den medizinischen Be-

61 Eine Aufstellung vom 1. August 1946 gibt 84500 sowjetische Bürger (ohne Wehrdienstleistende und Lagerinsassen) und 108500 Deutsche an. Vgl. Kostjašov, Zaselenie Kaliningradskoj oblasti, S. $82 \mathrm{f}$.

62 Vgl. Linck, Königsberg 1945-1948, S. 75, und Fisch, Schicksal der Deutschen, S. 399. Danach gab es im September/Oktober 1948 eine letzte große Aussiedlungswelle, mit der etwa 41000 Deutsche ausgesiedelt wurden. Im November 1949 - also über ein Jahr später - wurden dann 1400 und im Mai 1951 weitere 190 „Spezialisten“ ausgesiedelt, die bis zu diesem Zeitpunkt offensichtlich unabkömmlich gewesen waren.

63 Vgl. Luschnat, Lage der Deutschen, S. 96.

64 Vgl. Wieck, Zeugnis vom Untergang, S. 307.

65 Vgl. Linck, Königsberg 1945-1948, S. 80.

66 BMfV, Dokumentation, Bd. II, S. $144 \mathrm{f}$.

67 Deichelmann, Ich sah Königsberg sterben, S. 209.

68 Ebenda, S. 148. 
reich dokumentiert, da es allein drei Erinnerungs- bzw. Tagebücher gibt, die von leitenden deutschen Ärzten über die Nachkriegszeit in Kaliningrad geschrieben wurden. Sie berichten, daß das Personal der Krankenhäuser zunächst nur aus Deutschen bestand, denen lediglich ein sowjetischer Kommandant vorangestellt wurde ${ }^{69}$. Nach und nach seien auch die unteren Ebenen sowjetisiert worden, indem deutsche Ärzte und Krankenschwestern schrittweise durch sowjetisches Personal ersetzt wurden - beginnend mit den leitenden Positionen, wo die Ärzte zunächst zu Stellvertretern und dann zu Arbeitslosen wurden ${ }^{70}$.

Diese Verdrängung aus dem Arbeitsleben ist jedoch keineswegs ein Zeichen dafür, daß im Frühjahr 1947 der Zuzug von Sowjetbürgern so stark war, daß diese mit Deutschen durchgängig in Konkurrenz um knappe Arbeitsplätze traten. Im Gegenteil: Als zu dieser Zeit die ersten Projekte der Aussiedlung der deutschen Bevölkerung aus dem Kaliningrader Gebiet diskutiert wurden, warnten die Behörden des Gebietes vor einem zu hohen Tempo der Aussiedlung. So schrieb der Chef der Gebietsverwaltung für Zivilangelegenheiten, Vasilij A. Borisov, in einem Brief vom 7. März 1947 an Molotov, den Vertrauten Stalins und zu dieser Zeit Stellvertretender Vorsitzender des Ministerrates der UdSSR, daß die Deutschen im Kaliningrader Gebiet insgesamt 48 Prozent der Arbeitskräfte stellten und ihr Anteil in einzelnen Branchen sogar bis zu 90 Prozent betrage ${ }^{71}$. Dennoch wurde am 11. Oktober 1947 von Stalin ein Erlaß des Ministerrates der UdSSR unterzeichnet, der die „Übersiedlung der Deutschen aus dem Kaliningrader Gebiet der RSFSR in die sowjetische Besatzungszone Deutschlands“ - also ihre Deportation - anordnete ${ }^{72}$.

Noch im gleichen Monat begann der Abtransport der Deutschen - binnen zwei Monaten wurden mit 14 Zügen etwa 10000 Deutsche abgeschoben. In diesen ersten Transporten saßen neben den Bewohnern der Militärbasis Baltijsk (Pillau) und der strategisch bedeutenden Bezirke an der Ostsee vor allem Familien, „die nicht mit gesellschaftlich nützlicher Arbeit beschäftigt sind“, deutsche Kinder aus der Gebietswaisenhäusern und deutsche Rentner aus den Gebietsinvalidenhäusern ${ }^{73}$. Alle Aussiedler wurden vor ihrer Ausreise einer Überprüfung durch das MVD (Ministerstvo Vnutrenich Del - Innenministerium) und das MGB (Ministersvo Gosudarstvennoj Bezopasnosti - Ministerium für Staatssicherheit) unterzogen, deren Vertreter gemeinsam mit den Vertretern der Rayonsexekutivkomitees die Aussiedlung organisierten. Die Tätigkeit der Sicherheitsbehörden ist unter anderem an den erhaltenen Ausreiselisten abzulesen, auf denen alle

69 Ebenda, S. 6.

70 Ebenda, S. 9, 22.

71 Kostjašov, Vyselenie nemcev iz Kaliningradskoj oblasti, S. 187.

72 Ebenda.

73 Ebenda. 
nach Deutschland ausgesiedelten Personen mit Namen, Wohnort und Geburtsdatum verzeichnet wurden: Bei einigen Namen finden sich Vermerke wie „gestorben“, „[aus der Liste] herausgenommen“ (snjat) oder „[dem] MGB [übergeben]" 74 .

Nachdem 1947 somit vorrangig diejenigen Deutschen in die sowjetische Besatzungszone Deutschlands transportiert worden waren, die arbeitsunfähig waren, wurde per Erlaß des Ministerrates der UdSSR vom 15. Februar 1948 die Aussiedlung aller übrigen Deutschen aus dem Kaliningrader Gebiet angeordnet. In zwei Wellen wurden etwa 67000 Deutsche in Züge in Richtung Berlin gesetzt. Lediglich einige hundert Facharbeiter wurden, wie bereits erwähnt, teilweise noch bis 1951 festgehalten ${ }^{75}$. Diese letzte Facharbeiterreserve konnte jedoch nicht verhindern, daß sich die Befürchtungen der örtlichen Behörden über die negativen wirtschaftlichen Auswirkungen der von Moskau angeordneten Ausweisung der deutschen Bevölkerung aus dem Kaliningrader Gebiet bereits 1948 im vollen Umfang bestätigten: Am Ende dieses Jahres beschwerte sich der Kaliningrader Gebietsparteichef Ščerbakov bei Malenkov, dem Sekretär des ZK der KPdSU, daß sich in den Sovchosen und Industriebetrieben ein großer Mangel an Arbeitskräften bemerkbar mache, der sich im laufenden Jahr „durch die vollständige Ausweisung der deutschen Bevölkerung dramatisch verschärft hat" ${ }^{\text {"76. Es sollte }}$ nicht das letzte Mal sein, daß sich die Interessen der Staatsführung in Moskau und der Autoritäten im Kaliningrader Gebiet diametral gegenüberstanden.

Die Behandlung der deutschen Bevölkerung zeigt, daß ihre Aussiedlung anfangs anscheinend nicht vorgesehen war. Die Maßnahmen der sowjetischen Behörden in der unmittelbaren Nachkriegszeit weisen zumindest darauf hin, daß versucht wurde, die Deutschen in die neu entstehende Gesellschaft aus demobilisierten sowjetischen Soldaten und Neusiedlern aus dem Innern der Sowjetunion zu integrieren, bzw. durch politische Umerziehung durch die Veranstaltungen eines „Deutschen Klubs“ zu Sowjetbürgern zu machen ${ }^{77}$. Trotz Arbeitszwang waren die Deutschen somit keine Zwangsarbeiter. Im Gegensatz zur Zeit vor dem April 1945 gab es im Alltagsleben von Deutschen und Sowjets zahlreiche Berührungspunkte: Nachdem die neuen Machthaber in den ersten Monaten nach der Eroberung Königsbergs noch geplant hatten, die Deutschen in „speziell abgetrennten

74 Ebenda.

75 Kostjašov, Vyselenie nemcev iz Kaliningradskoj oblasti, S. 188.

76 CChIDNIKO, f. 1, op. 2, d. 55, Bl. 86 f., hier: Bl. 86. Auf dieses Dokument machte mich Per Brodersen aufmerksam.

77 Der Deutsche Klub hieß ursprünglich „Antifaschistischer Klub“, wurde aber in der (wie sich später herausstellte: trügerischen) Hoffnung umbenannt, auf diese Weise größere Anziehungskraft auf die deutsche Bevölkerung auszuüben. Vgl. dazu: Luschnat, Die Lage der Deutschen, S. 167-170, und Deichelmann, Ich sah Königsberg sterben, S. 91-93. 
Stadtbezirken“ - also Gettos - zusammenzuführen ${ }^{78}$, lebten Deutsche und Sowjets später häufig unter einem Dach, arbeiteten für den gleichen Lohn und halfen gemeinsam bei den Aufräumarbeiten in der Stadt. Obwohl die sowjetischen Behörden versuchten, die Lebens- und Arbeitsbedingungen für deutsche Geistliche zu erschweren, um die Gemeindearbeit schrittweise zurückzudrängen, bestand zudem die Möglichkeit der Religionsausübung bis zur Aussiedlung der Deutschen im Jahre 1948 fort $^{79}$. Es läßt sich ferner zwar eine schrittweise Verdrängung der Deutschen aus allen leitenden Positionen feststellen, in denen sie nach der Eroberung Ostpreußens durch die Rote Armee aufgrund ihrer Fachkenntnisse noch verblieben waren - diese Verdrängung war jedoch bis zum Moskauer Deportationsbeschluß offensichtlich nicht mit dem Ziel verbunden, die Deutschen auch aus dem ehemaligen Ostpreußen insgesamt zu verdrängen.

So wie die sowjetische Politik gegenüber den im nördlichen Ostpreußen verbliebenen Deutschen zunächst in erster Linie dadurch bestimmt wurde, daß ihre Arbeitskraft noch benötigt wurde, so richtete sich auch die Besiedlung des Kaliningrader Gebietes mit sowjetischen Bürgern im ersten Nachkriegsjahr vorrangig nach den Bedürfnissen der örtlichen Industrie. Schon wenige Wochen nach der Eroberung Königsbergs inspizierten Spezialisten der Moskauer Volkskommissariate die Industrieanlagen, um abzuschätzen, welche von ihnen wenig beschädigt waren und deshalb bald wieder in Betrieb genommen werden konnten. Von besonderem Interesse waren hier die Werft (die frühere „Schichau-Werft“ erhielt nach 1945 die Tarnbezeichnung „Werk No. 820“) und die Papierfabriken. Neben deutschen Zivilisten setzte die Militärverwaltung für die Wiederinbetriebnahme dieser Industrieanlagen zunächst demobilisierte sowjetische Soldaten, sogenannte „Repatriierte“, also aus Deutschland zurückgekehrte ehemalige sowjetische Kriegsgefangene oder Zwangsarbeiter, und deutsche Kriegsgefangene ein ${ }^{80}$. Außerdem ließ das Staatliche Verteidigungskomitee im Juli 1945 aus den Wehrdienstleistenden der Roten Armee Bauarbeiter aussuchen und in sieben Einheiten (etwa 2860 Mann) zur Aufbauarbeit nach Königsberg verlegen ${ }^{81}$. Der Einsatz von sowjetischen Soldaten für den provisorischen Wiederaufbau blieb in der Nachkriegszeit üblich: So wurde das ehemalige Waggonbauwerk „Steinfurt“ mit Hilfe von Einheiten der Baltischen Flotte seit März 1946 rekonstruiert ${ }^{82}$.

Auch die zuständigen Volkskommissariate in Moskau delegierten in der Anfangsphase Arbeiter in die von ihren Spezialisten ausgesuchten Industriebetriebe; so wurden dem kaum zerstörten Zellstoffwerk in Königsberg

\footnotetext{
78 Vgl. Fisch/Klemeševa, Schicksal der Deutschen, S. 393.

79 Luschnat, Lage der Deutschen, S. 145-165.

80 Isupov, Vostočnaja Prussija, S. 454.

81 Ebenda, S. 454.

82 Ebenda, S. 455.
} 
bereits im September 1945 mehrere hundert Arbeiter zugeteilt, die eine zügige Produktionsaufnahme sichern sollten. Ihnen folgten ein halbes Jahr 250 weitere Arbeiter, die das Waggonbauwerk wiederherrichten sollten. Im Laufe des Jahres 1946 kamen in diesem Betrieb weitere 500 Arbeiter und 200 demobilisierte Soldaten zum Einsatz ${ }^{83}$. Schließlich schickten noch die Betriebe selbst Anwerber in die Industriezentren der Sowjetunion, um Arbeitskräfte zu rekrutieren. $\mathrm{Da}$ zu dieser Zeit in ganz Rußland für verschiedene Gebiete Werbekampagnen liefen, traten die Anwerber häufig in Konkurrenz zueinander und versuchten, sich mit verschiedenen Versprechungen gegenseitig die Arbeiter abzuwerben. Die Umsiedlungswilligen kamen dadurch in die ungewohnte Situation, sich das beste Angebot aussuchen zu können. So berichtete eine Frau über ihre Anwerbung in dem Verwaltungsgebäude ihres Heimatortes: „Als wir dort ankamen, waren dort gleich drei Anwerber auf einmal. Sie überredeten uns um die Wette, in die neuen Gebiete zu fahren. [...] Es interessierte sie nicht einmal, welche Berufe die potentiellen Umsiedler hatten. Sie sagten: Wenn du keinen Beruf hast, kannst du ihn im dortigen Betrieb erlernen. Jeder Anwerber versuchte, die Leute zu überreden, in seine Gegend zu fahren. Einer von ihnen sagte zu uns: ,Mädchen! Wozu wollt ihr nach Kaliningrad fahren? Dort müßt ihr doch Schiffe unter freiem Himmel zusammenbauen.' Aber wir beschlossen trotzdem, nach Kaliningrad zu fahren. Uns hat ein Anwerber aus dem Betrieb 820 überredet [...]. Seine Argumente schienen uns am überzeugendsten. Obwohl seine Konkurrenten betonten, daß wir bei ihnen Reisegelder und eine Wohnung bekämen. “84

Noch bevor im Sommer 1946 die offizielle Umsiedlungskampagne begonnen hatte, übersiedelten auf diese Weise im ersten Jahr nach der Besetzung Königsbergs monatlich bis zu 4000 sowjetische Bürger in das spätere Kaliningrader Gebiet. Zum 7. April 1946, dem Tag der Gründung des Gebietes, waren bereits 41000 Sowjetbürger im Gebiet registriert, und die Dynamik der Zuwanderung nahm noch weiter zu: Zum 1. Juni 1946 stieg die Zahl der sowjetischen Neubürger auf 53000 und zum 1. August 1946 auf 84000 . Von ihnen waren etwa ein Fünftel sogenannte Repatriierte. Trotz dieser relativen Zuwanderungsdynamik blieben die Sowjetbürger im Gebiet

83 Kaliningradskaja oblast', S. 23. Die dort genannte und von Wörster, Besiedlung, S. 128, übernommene Zahl von angeblich 9500 in die Papierindustrie delegierten Facharbeitern kann nicht stimmen, da dies bereits ein Viertel der gesamten im April 1946 im Königsberger Gebiet registrierten Sowjetbürger ausmachen würde, zu denen auch die Familien der Arbeiter gehören. Wahrscheinlich muß man eine Null streichen. An dieser Stelle sei darauf hingewiesen, daß die meisten sowjetischen Statistiken dieser Jahre Rechenfehler aufweisen. Für sie gilt deshalb, daß sie lediglich als Annäherungswerte zu begreifen sind, die Tendenzen aber keine absoluten Werte vermitteln.

84 Matthes, Als Russe in Ostpreußen, S. 37. 
allerdings deutlich in der Minderheit, da die Zahl der Deutschen noch bei zirka 108000 lag $^{85}$.

Im Sommer wurde die Besiedlung des Kaliningrader Gebietes, die bis dahin im wesentlichen entweder von den einzelnen Militärbehörden, Volkskommissariaten und Betrieben dezentral organisiert worden war oder von der persönlichen Initiative der sowjetischen Umsiedler getragen wurde, durch eine zentral gesteuerte Umsiedlungskampagne ergänzt. Dieser Schritt hatte sehr unterschiedliche Ursachen. Zum einen stellte die unkontrollierte, auf Eigeninitiative der Umsiedler beruhende Besiedlung des Gebietes für die sowjetischen Behörden ein hohes Maß an Unsicherheit dar. Ein geheimer Erlaß der sowjetischen Regierung erklärte deshalb am 29. Juni 1946 das gesamte Kaliningrader Gebiet zum Grenzsperrgebiet, in dem sich sowjetische Zivilisten nur noch mit Genehmigung der Miliz aufhalten durften ${ }^{86}$. Jeder Umsiedlungswillige wurde von nun an einer heimlichen Überprüfung unterzogen, um „Heimatverräter, Schwerverbrecher und unzuverlässige Elemente" herauszufiltern. Auf Grund dieser Überprüfungen wurden in den verschiedenen Bezirken des Gebietes zwischen drei und zwölf Prozent der sowjetischen Umsiedlungsbewerber abgelehnt ${ }^{87}$. In den Listen, die die Statistikabteilung des Kaliningrader Gebietes anlegte, wurde sorgfältig vermerkt, aus welchen Gründen eine Person verdächtig erschien. Besonders argwöhnisch wurden in diesem Zusammenhang die Repatriierten beobachtet, da sie während des Krieges als Kriegsgefangene oder sogenannte „Ostarbeiter" in Deutschland gewesen waren - und somit lange Zeit der kommunistischen Kontrolle entzogen waren. Vor ihrer „Repatriierung“ mußten sie deshalb ein „Überprüfungs- und Filtrierlager" durchlaufen ${ }^{88}$.

Auch die Tatsache, daß trotz des schon beträchtlichen Zustroms von sowjetischen Bürgern die Deutschen im Sommer 1946 immer noch die Bevölkerungsmehrheit bildeten, dürfte ein Argument für eine rasche, zentralisierte Umsiedlungskampagne gewesen sein, da die deutsche Zivilbevölkerung auch über ein Jahr nach Kriegsende als Sicherheitsrisiko eingeschätzt wurde. Die Entscheidung für die Umsiedlungskampagne dürfte jedoch wesentlich durch den immer noch beträchtlichen Mangel an (qualifizierten) Arbeitskräften im Gebiet beeinflußt worden sein. Zusammen-

$85 \mathrm{Vgl}$. Aufstellung der Statistikverwaltung des Kaliningrader Gebietes, in: GAKO, f. 181, op. 1, d. 10, 1. 22, und Kostjašov, Zaselenie Kaliningradskoj oblasti, S. 82.

86 Der Passus, wonach nur Arbeiter mit gültigen Pässen zur Arbeit in Betrieben angenommen werden durften, wurde in der Anordnung der Verwaltung für Zivilangelegenheiten über die Registrierung der Bevölkerung Kaliningrads vom 12. Juli 1946 allerdings durchgestrichen. Vgl. GAKO, f. 298, op. 1, d. 4, 1. 10. Kostjašov, Zaselenie Kaliningradskoj oblasti, S. 84, weist darauf hin, daß Behörden und Betrieben aufgrund des Arbeitskräftemangels „häufig gezwungen waren, Formalitäten nicht zu beachten".

87 Kostjašov, Zaselenie Kaliningradskoj oblasti, S. 83, und Matthes, Als Russe in Ostpreußen, S. 44-48.

88 Vgl. Zubkova, Sowjetische Gesellschaft, S. 372 f., und dies., Russia after the war, S. 105 f. 
gerechnet betrug die Anzahl der Deutschen und Sowjetbürger im August 1946 zwar bereits etwa 193000 Personen (ohne Militär) ${ }^{89}$, doch war dies erst ein Bruchteil der Vorkriegsbevölkerung, die 1939 allein in Königsberg etwa 370000 betragen hatte. Zudem machte sich auch im Kaliningrader Gebiet die Landflucht bemerkbar, die in der ganzen Sowjetunion zu beobachten war. Im Kaliningrader Gebiet äußerte sich dies allerdings vor allem darin, daß der entvölkerte ländliche Raum überhaupt gar nicht erst besiedelt wurde.

Um diesen Umstand abzuhelfen, wurde am 3. Juli 1946 bei der Gebietsverwaltung eine Kommission für Umsiedlerfragen eingerichtet ${ }^{90}$. Ihm standen der Chef der Gebietsverwaltung für Zivilangelegenheiten und der Chef der Politabteilung der Gebietsverwaltung vor, bzw. nach der Umstellung der Verwaltung der Vorsitzende des Gebietsexekutivkomitees und der Gebietsparteichef. Die Einbeziehung der Politabteilung bzw. der Partei sollte sicherstellen, daß die Wahrnehmung des Gebietes durch die Neusiedler sofort nach deren Ankunft ensprechend der offiziellen Parteilinie beeinflußt wurde und eventuell „entstehende Fragen“ beantwortet werden konnten ${ }^{91}$. Wenige Tage nach der Gründung der Umsiedlungsbehörde gab Stalin mit seiner Unterschrift unter den Erlaß des Minsterrates der UdSSR „Über die ersten Maßnahmen zur Besiedlung der Rayons und der Entwicklung der Landwirtschaft im Kaliningrader Gebiet" vom 9. Juli 1946 den offiziellen Startschuß für die Besiedlung des ländlichen Raumes. In diesem Erlaß wurde bestimmt, daß von August bis Oktober 194612000 Kolchosfamilien umgesiedelt werden sollten, und festgelegt, woher diese kommen sollten ${ }^{92}$. Um die freiwillige Übersiedlung in das neue Gebiet zu erleichtern, wurden den Familien zahlreiche Vergünstigungen eingeräumt: Neben der kostenlosen Reise wurden die Übersiedler für einige Zeit von der Steuer befreit, erhielten Startkapital, und jeder Familie wurden jeweils ein eigenes Grundstück von einem halben Hektar und ein Haus, die auf dem Land zahlreich leerstanden, als persönlicher Besitz zugeteilt ${ }^{93}$. Am 23. August $1946 \mathrm{kam}$ der erste Umsiedlerzug in Gumbinnen an, mit dem 160 Familien von Kolchosbauern aus dem Brjansker Gebiet eintrafen. Bis Ende 1946 gelangten so 12024 Familien in das Kaliningrader Gebiet und wurden auf 295 neugegründete Kolchosen verteilt ${ }^{94}$. In jedem Rayon des Gebietes wurde zunächst ein Sammellager errichtet, das die Neuankömmlinge aufnehmen sollte und von wo aus diese auf die Dörfer und Städte verteilt wurden. Um

89 Vgl. Kostjašov, Zaselenie Kaliningradskoj oblasti, S. 83.

90 Isupov, Samaja zapadnaja, No. 5, S. 19.

91 Istorija Kraja, S. 56.

92 Isupov, Samaja zapadnaja, Bd. I, No. 19, S. 30-35.

93 Vgl. Kostjašov, Zaselenie Kaliningradskoj oblasti, S. 83, und Matthes, Als Russe in OstpreuBen, S. 39-44.

94 Vgl. Kostjašov, Zaselenie Kaliningradskoj oblasti, S. 83, und Istorija Kraja, S. 56. 
die Besiedlung des Gebietes weiter zu forcieren, sollten die Umsiedler möglichst bald nach ihrer Ankunft Briefe an ihre Verwandten schreiben bzw. unterschreiben, in denen das neue Gebiet in den schönsten Farben geschildert wurde. Viele dieser Briefe wurden sodann in den Zeitungen ihrer Heimatgebiete veröffentlicht, um weitere Personen zur Ansiedlung zu veranlas$\operatorname{sen}^{95}$.

Insgesamt steigerte sich die Bevölkerungszahl in den ländlichen Regionen des Gebietes in der zweiten Jahreshälfte 1946 um mehr als 58000 Menschen. Das Ziel, den Bevölkerungszuwachs stärker auf das Land umzuleiten, wurde jedoch weit verfehlt. Die ländlichen Neusiedler bildeten nur einen vergleichsweise geringen Teil der Gesamtzahl der Neusiedler. Wurden zum 1. August 1946 noch 84500 sowjetische Bürger im Gebiet gezählt, waren es am 1. Januar 1947 schon 278000 - die 58000 Bauern machten von den insgesamt knapp 200000 Neubürgern des Gebietes also nur etwas über ein Viertel aus ${ }^{96}$. Auch in einer anderen Hinsicht läßt sich beobachten, daß die zentralisierte Anwerbung von Übersiedlern für die Besiedlung des Kaliningrader Gebietes keine von vorrangiger Bedeutung war: In zweien der drei Gebiete der RSFSR, aus denen die meisten Übersiedler gekommen waren, hatten überhaupt keine staatlich koordinierten Werbungskampagnen stattgefunden ${ }^{97}$.

Die Umsiedlungswelle in die Städte des Kaliningrader Gebietes ebbte allerdings ebenso schnell ab wie die in die ländlichen Regionen: Zum 1. Januar 1950 lebten im Gebiet insgesamt erst 407000 (nach anderen Angaben immerhin 479000) sowjetische Bürger. Die etwa 200000 Neusiedler, die im zweiten Halbjahr 1946 kamen, stellen somit fast die Hälfte aller Übersiedler der gesamten Phase der Massenbesiedlung der Jahre 1945 bis 1950 dar ${ }^{98}$. Mit der ersten Welle war der Höhepunkt der Besiedlung daher auch schon überschritten 99 .

Der Einbruch im Bevölkerungszufluß mag auch mit den enormen Problemen zusammenhängen, die die plötzliche Ankunft von Zehntausenden von Neusiedlern im Kaliningrader Gebiet auslösten: In den Städten wurde der

95 Isupov, Samaja zapadnaja, Bd. I, No. 29-32, S. 45-48.

96 Kostjašov, Zaselenie Kaliningradskoj oblasti, S. 85.

97 Ebenda, S. 84.

98 Ebenda, S. 85.

99 Auch die Ansiedlung von ehemaligen Insassen des Arbeitslagers in Palmniken/Jantarnyj dürfte das Bevölkerungswachstum nur unwesentlich gesteigert haben, da sich im Lager, das von Juli 1949 bis zum April 1953 bestand, nie mehr als zirka 2700 (1948), seit 1950 aber nur noch zirka 1500 Insassen befanden. Vgl. Smirnov, Sistema ispravitel'no-trudovych lagerej v SSSR, S. $166 f$.

Die Herkunft der Neusiedler läßt sich anhand der Listen, die die Statistikabteilung der Kaliningrader Gebietsabteilung bis in die 50er Jahre hinein führte, recht genau nachvollziehen (GAKO, f. 181). Demnach kamen über 70 Prozent der Neusiedler aus Rußland, jeweils etwa 10 Prozent aus Weißrußland und der Ukraine. Vgl. Brodersen, Das Werk 820, und Matthes, Als Russe in Ostpreußen, S. 496-501. 
Wohnraum immer knapper, was sich für die Deutschen dahingehend auswirkte, daß sie zunehmend aus ihren Wohnungen verdrängt und in Kellern oder Dachböden einquartiert wurden ${ }^{100}$. Vor allem aber reichten die Nahrungsmittelvorräte im Gebiet für die vielen Neusiedler nicht mehr aus. Die neuangeworbenen Kolchosbauern konnten jedoch noch keine neuen Lebensmittel produzieren, da sie größtenteils im Herbst ankamen, also am Ende der Saison. Die Folge dieser Überlastung war die schwere Hungersnot im Winter 1946 und Frühling 1947101. Außerdem kam es nun zu den bereits erwähnten ersten Engpässen auf dem Arbeitsmarkt für ungelernte Arbeitskräfte: Es stellte sich heraus, daß viele Neusiedler überhaupt nicht die Berufsbildung besaßen, die sie bei der Anwerbung angegeben hatten. Selbst nach offiziellen Angaben waren ein Sechstel der Neusiedler, die sich als Bauern beworben hatten, in Wirklichkeit Stadtbewohner; Zeitzeugen berichten, daß dieser Anteil wahrscheinlich bei über 50 Prozent lag. Wie die oben beschriebenen Anwerbungsmethoden der Betriebe des Kaliningrader Gebietes zeigen, war die Situation in der Industrie nicht wesentlich besser ${ }^{102}$.

Auch die soziale Zusammensetzung der Neusiedler entsprach häufig nicht den Vorstellungen der Regierung. In den entsprechenden Erlassen, die die Besiedlung des Gebietes regelten, war vorgesehen, daß nur solche Familien in den Genuß der vom Staat versprochenen Vergünstigungen kamen, zu denen mindestens zwei arbeitsfähige Personen gehörten. Im Gebiet kamen nun aber eine große Anzahl „unvollständiger Familien“ an - in der Regel waren dies alleinerziehende Mütter -, oder es wurden auf den Fragebögen minderjährige oder invalide Familienmitglieder als arbeitsfähig angegeben ${ }^{103}$. Auf diese Weise spiegelte sich im sozialen Profil der Ankömmlinge die vom Krieg zerrüttete sowjetische Gesellschaft wider, insbesondere das aus den Fugen geratene Gleichgewicht der Geschlechter: Die sowjetische Nachkriegsgesellschaft war, wie die russische Historikerin Elena Zubkova unlängst feststellte, eine „vorwiegend weibliche Gesellschaft“. Während 1940 in der Altergruppe von 20 bis 44 Jahren in der Sowjetunion noch 37,6 Millionen Frauen 34,8 Millionen Männer gegenüberstanden, hatte sich dieses Verhältnis 1946 dramatisch verschoben. In diesem Jahr wurden in der gleichen Altersgruppe 37,7 Millionen Frauen, aber nur noch 25 Millionen Männer gezählt ${ }^{104}$.

Es ist aufgrund der sozialen Situation in der Sowjetunion der Nachkriegsjahre wenig überraschend, daß gerade diejenigen von den Werbekampagnen der Regierung und der Betriebe besonders angezogen wurden, die eigentlich

$100 \mathrm{Vgl}$. Matthes, Als Russe in Ostpreußen, S. 317-319.

101 Vgl. Kostjašov, Zaselenie Kaliningradskoj oblasti, S. 85.

102 Ebenda.

103 Vgl. ebenda, S. 87.

104 Vgl. Zubkova, Die sowjetische Gesellschaft nach dem Krieg, S. 365. 
gar nicht gewollt waren: die Schwachen und Armen. Die Aussicht auf das von den Anwerbern versprochene Haus oder eine Wohnung und Lebensmittelunterstützung erschien vor allem den Bewohnern der Gebiete Weißrußlands, der Ukraine und Rußlands verlockend, über die während des Krieges mehrmals die Front hinweggezogen war ${ }^{105}$. Tatsächlich war die Aussicht auf eine Verbesserung der persönlichen Lebensbedingungen die wesentliche Motivation für die meisten Neusiedler, in das unbekannte Land an der Ostsee zu ziehen. Politischer Enthusiasmus, der den Neusiedlern in der sowjetischen Literatur als hauptsächlicher Beweggrund für ihre Teilnahme am Wiederaufbau Kaliningrads unterstellt wurde, spielte bei nur einem geringen Anteil von ihnen tatsächlich eine Rolle106.

Die Realität, mit der die Neuankömmlinge konfrontiert wurden, entsprach jedoch selten den zuvor gehegten oder erweckten Erwartungen: Häufig beschwerten sich die Arbeiter über gebrochene Versprechen der Anwerber und beklagten sich über dreckige Wohnheime und schlechte Verpflegung107. Mitunter wurden besonders abschreckende Beispiele ausführlich in der Lokalpresse verurteilt. Die Kaliningradskaja Pravda berichtete am 18. Mai 1948 über die Ankunft von 40 Arbeitern, die dem Elektrizitätswerk zugeteilt wurden, dessen Leitung auf deren Unterbringung jedoch völlig unvorbereitet gewesen sei: Auf Anweisung des Direktors des Werkes habe man „in aller Eile die Fenster eines der halbzerstörten Häuser vernagelt und es als Wohnheim bezeichnet. Die vorhandene Bettwäsche verteilte man unter den Ankömmlingen. Der eine bekam ein Kissen, die zweite die Matratze, der dritte ein Laken"108. Die Wohn- und Lebensbedingungen führten zu ernsthaften Gesundheitsschäden unter den Neusiedlern. 1947 wurde bei einer medizinischen Reihenuntersuchung der etwa 500 Arbeiter des Waggonbauwerkes festgestellt, daß von diesen 63 an Mangelernährung und 60 an Unterernährung litten und 3 Personen an Tuberkulose erkrankt waren. Unter den Arbeitern der Werft Nr. 820 traten in den Jahren 1947/48 zahlreiche Fälle von Typhus und Malaria auf, so daß die Werksleitung in einem Bericht an die Gebietsparteileitung bereits von einer Epidemie sprach $^{109}$.

Die Enttäuschung über die Zustände im Kaliningrader Gebiet war insbesondere unter den Repatriierten zu spüren. Obwohl sie in der nationalsozialistischen „Rassentheorie“ als „Untermenschen“ auf der untersten

105 Vgl. Kostjašov, Zaselenie Kaliningradskoj oblasti, S. 87.

106 Die von Kolganova, Obrazavanie i stanovlenie Kaliningradskoj oblasti, S. 37-64, angegebenen kumulierten Aussagen von Motiven von Neusiedlern für ihren Umzug nach Kaliningrad (Wille, am Aufbau des Sozialismus mitzuwirken, usw.) entsprechen, wie Per Brodersen festgestellt hat, nicht den ihrer Arbeit zugrundeliegenden Fragebögen. Vgl. GAKO, f. 20, op. 1, d. 5.

107 Vgl: CChIDNIKO, f. 1, op. 9, d. 86, 1. 33 f.

108 Zitiert nach: Matthes, Als Russe in Ostpreußen, S. 77.

109 Vgl. Prošina, Problemy zaselenija Kaliningradskoj oblasti, S. 18. 
Stufe der Werteskala standen und deshalb in deutscher Gefangenschaft in der Regel äußerst schlecht behandelt worden waren, hatten sie doch den Wohlstand im kapitalistischen Deutschland vor seiner Zerstörung aus nächster Nähe betrachten können: Ihre Berichte von den sauberen Straßen und reichen Bauernhöfen bildeten einen starken Kontrast zu der erfahrenen Realität im Kaliningrader Gebiet ${ }^{110}$. Ihre Unzufriedenheit äußerte sich u. a. dadurch, daß sich viele Repatriierte weigerten, an den ersten Wahlen zu den Gebietskörperschaften im Jahre 1947 teilzunehmen, und dies gegenüber Wahlhelfern offen mit der Feststellung begründeten, daß „sie hier unter schlechten Bedingungen lebten"111. Insofern war das Mißtrauen, das den Repatriierten von den Machtorganen entgegengebracht wurde, durchaus verständlich. Sie stellten für ihre Landsleute „eine Quelle ungefilterter Information über das Leben jenseits der Grenzen der UdSSR dar"112. Die Unzufriedenheit der Sowjetbürger, die aus deutscher Gefangenschaft zurückkamen, war somit eine potentielle Gefahr für den sozialen Frieden.

Bedrohlicher aber als die vergleichsweise gut informierten und deshalb unzufriedenen Repatriierten wurden jedoch die schlecht informierten und trotzdem unzufriedenen Sowjetbürger aus dem Landesinneren. Sie legten sich angesichts des schleppenden Fortganges des Wiederaufbaus eigene Erklärungen zurecht für die vermeintliche Unlust des Staates, in das Kaliningrader Gebiet zu investieren. Dabei entstanden immer wieder wilde Gerüchte über die Zukunft des ehemaligen Ostpreußen. In einem Bericht über die politische Stimmung im Gebiet, den das Gebietsparteikomitee Anfang Mai 1947 für das ZK der VKP(b) verfaßte, wurde z. B. die Bemerkung eines Ingenieurs der städtischen Druckerei über die Ergebnisse des Besuches des sowjetischen Ministerpräsidenten mit den Worten zitiert: „Kosygin hat sich [bei seinem Besuch in Kaliningrad] selbst überzeugt, daß Kaliningrad Hilfe braucht, aber offensichtlich fürchtet er sich, dies zu tun, weil mit der Zeit Kaliningrad wieder an die Deutschen fällt."113 Paradoxerweise sind gerade Gerüchte dieser Art ein Zeichen für die bereits weitgehende Sowjetisierung des Kaliningrader Gebietes. Angesichts des Informationsvakuums und der im Zeichen des beginnenden Kalten Krieges stehenden sowjetischen Propaganda-Losung der „feindlichen Einkreisung“ waren im Rußland der Nachkriegszeit Mutmaßungen insbesondere über einen bevorstehenden Krieg mit dem Westen weit verbreitet ${ }^{114}$. Die Kaliningrader Besonderheit lag

110 Vgl. Zubkova, Die sowjetische Gesellschaft nach dem Krieg, S. 372-375, die in ihrem Aufsatz die Lage in der gesamten Sowjetunion betrachtet.

111 Matthes, Als Russe in Ostpreußen, S. 224. Allgemein zur Situation der Repatriierten in der Sowjetion in der Nachkriegszeit: Zubkova, Sowjetische Gesellschaft, S. $372 \mathrm{f}$.

112 Zubkova, Sowjetische Gesellschaft, S. 373.

113 CChIDNIKO, f. 1, op. 1, d. 58, 1. 3. Auf dieses Dokument machte mich Per Brodersen aufmerksam.

114 Vgl. Zubkova, Russia After the War, S. 83-85. 
lediglich darin, daß sich die Neusiedler in dem „westlichen Vorposten“ der Sowjetunion ${ }^{115}$ als wahrscheinliche erste Opfer eines solchen Krieges sahen ${ }^{116 .}$

Viele Neusiedler kehrten auf Grund ihrer Enttäuschungen wieder in ihre alte Heimat zurück. „Nicht alle hatten die Tapferkeit, fern von der alten Heimat unter ungewohnten klimatischen und geografischen Bedingungen das vom Krieg gezeichnete Land wieder zum Leben zu erwecken“, wurde in einem Lehrbuch der Kaliningrader Universität Mitte der 80er Jahre diese Entwicklung in der Nachkriegszeit kommentiert ${ }^{117}$. Für die Jahre 1948-1950 gibt es genaue Zahlen über den Wegzug der Neusiedler: Laut den Statistiken der Kaliningrader Gebietsverwaltung kehrten insgesamt 36,7 Prozent der Neusiedler in dieser Zeit dem Kaliningrader Gebiet wieder den Rücken ${ }^{118}$. Die ländlichen Regionen des Kaliningrader Gebietes waren von der Abwanderung der Neusiedler wiederum sehr viel stärker betroffen als die Städte, da viele bäuerliche Arbeiter zwar nicht das Gebiet verließen, jedoch in die Städte zogen. Trotz dieses Zustromes vom Land standen die Industriebetriebe dort allerdings prinzipiell vor dem gleichen Problem wie die Sovchosen und Kolchosen: Auch sie hatten mit einer enormen Fluktuation zu kämpfen.

\section{Die böse Stadt}

\section{Der Vorposten des Militarismus}

Es scheint fast so, als hätten die sowjetischen Machthaber zunächst keine Konzepte für ihre neue Stadt gehabt, als seien sie sich unsicher gewesen, was für eine Rolle diese Erwerbung in der Zukunft spielen sollte. Ein deutliches Zeichen dafür sind auch die tastenden Konzeptionen für den Wiederaufbau Kaliningrads in der unmittelbaren Nachkriegszeit: Während Moskauer Architekten für viele sowjetische Städte schon Planungen für den Wiederaufbau vorbereiteten, als diese noch von den Deutschen besetzt waren ${ }^{119}$, mußten sich die Planer im späteren Kaliningrad erst noch über die Prämissen eines Wiederaufbaus einigen.

115 Vgl. „Der westliche Vorposten unserer Heimat“, in: Kaliningradskaja Pravda, 2. November 1948.

116 Näheres dazu im Teil II dieser Arbeit.

117 Istorija Kraja. 1945-1950, Kaliningrad 1984, S. 75.

118 Kostjašov, Zaselenie Kaliningradskoj oblasti, S. 86.

119 Die Luftwaffe der Roten Armee soll ihre Aufklärungsaufnahmen der noch von den Deutschen besetzten Stadt Smolensk dem mit der Wiederaufbauplanung beauftragten Architekten G. P. Gol'c zur Verfügung gestellt haben, damit er feststellen konnte, welche Gebäude beim Wiederaufbau verwendungsfähig und welche zu stark zerstört waren. Vgl. Belov, Podnjatye iz ruin, S. 44-49 und $199 \mathrm{f}$. 
Um diese Prämissen festzulegen, kam es zunächst zu einer heftigen Abrechnung mit der deutschen Geschichte Königsbergs. Diese gleichsam ideologische Katharsis der Stadt wurde zur Grundlage für die weitere Planung. Schon wenige Tage nach der Einnahme der Stadt erschien am 13. April 1945 in der Pravda eine Deutung der Geschichte Königsbergs, die für die folgenden Jahre maßgeblich bleiben sollte: „Königsberg - das ist die Geschichte der Verbrechen Deutschlands. Während ihrer vielhundertjährigen Geschichte lebte die Stadt mit Kämpfen und Überfällen, ein anderes Leben war ihr nicht vergönnt. Schweigsam und düster sind hier die Paläste. In ihren stillen Kabinetten, Kriegsarchiven und Bibliotheken, hinter den dicken Mauern von Kriegsschulen und Auditorien wurden von Jahrzehnt zu Jahrzehnt Kriege und Raubzüge vorbereitet. Um die Stadt herum entstanden die massiven Bauten des Befestigungsringes. Im Zentrum der Hauptstadt steht eine Zitadelle aus spitz zulaufendem Stein und von ungeheurem Ausmaß, in sie sind Gänge, Kasematten und Galerien eingelassen, gemeißelt und geschlagen. Sie reichen bis tief unter die Erde. ${ }^{120}$

Diese Beschreibung des alten Königsberg klingt, als sei sie aus einem Sagenbuch entnommen, so negativ idealisiert erscheint die Stadt in diesem Text, so schemenhaft wird sie beschrieben. Insofern begann hier ein Prozeß, der analog zu dem verlief, der etwas später auch in West-Deutschland einsetzte, nachdem 1948/49 die meisten Deutschen das Kaliningrader Gebiet verlassen hatten: Die deutsche Geschichte Königsbergs erstarrte zu einem Bild, das mit der realen Vergangenheit der Stadt nur noch bedingt in Verbindung stand. Während von den deutschen Heimatvertriebenen ein geschöntes Bild der ehemaligen Hauptstadt Ostpreußens gezeichnet wurde, bemühte sich die sowjetische Seite, einen nicht zu hinterfragenden Mythos von der „bösen Stadt“ zu schaffen. Die deutsche Vergangenheit sollte stigmatisiert werden, um die Inbesitznahme Königsbergs und seine Umformung in das sowjetische Kaliningrad zu rechtfertigen.

Allerdings war der Blick auf die Ruinen deutscher Städte auch bei den westlichen Alliierten noch im wesentlichen vom gerade beendeten Krieg geprägt, den die Deutschen vom Zaune gebrochen hatten. Die gründlich zerbombten Städte wurden für die Verbrechen der Deutschen haftbar gemacht, als seien sie selbst handelnde Personen in diesem Krieg gewesen. Die Verdammung Königsbergs in der sowjetischen Propaganda der Nachkriegszeit nimmt sich vor diesem Hintergrund nicht besonders extrem aus. Eine ähnliche Fokussierung auf den vermeintlich schlechten Charakter einer Stadt wie bei Königsberg läßt sich vor allem im Falle Berlins beobachten. Wenige Tage nach der Kapitulation der Wehrmacht sah die New York Times in der

120 Aus: V. Veličko, Padenic Kenigsberga, in: Pravda, 13. April 1945. [Teil 3 der Artikelserie zur Erstürmung Königsbergs durch die Rote Armee am 10. April 1945. Die anderen Artikel dieser Serie erschienen am 11., 12., 15. und 16. April 1945.] 
Auslöschung der deutschen Hauptstadt eine Vorbedingung für den Beginn einer erneuten Zivilisierung des Landes: Nur „sehr wenige Menschen würden das Verschwinden dieses unliebsamen Parvenüs unter den europäischen Hauptstädten bedauern" 121 .

Die Rolle der Stadt als Militärbasis des Deutschen Reiches nahm bei ihrer Dämonisierung einen zentralen Platz ein, wie die Betonung der Kriegsvorbereitungen in den „schweigsamen und düsteren Palästen“ von Königsberg deutlich macht. Man konnte dabei auf Interpretationen zurückgreifen, die während der gespannten Lage zwischen Deutschland und der Sowjetunion in den 30er Jahren vor Abschluß des Hitler-Stalin-Paktes entwickelt worden waren: Bereits in dem Artikel „Königsberg“ der ersten Auflage der Großen Sowjet-Enzyklopädie (Bolšaja Sovetskaja Enciklopedija, Band 31 von 1936) wurde auf die starken Befestigungsanlagen der Stadt hingewiesen, die seit Mitte des 19. Jahrhunderts rund um Königsberg entstanden waren. In der Verstärkung dieser Befestigungsanlagen nach dem Ersten Weltkrieg sahen die Autoren damals einen Hinweis für eine von der Stadt ausgehende Bedrohung und ihren offensiven Charakter: „Königsberg kann der deutschen Armee als Stützpunkt bei ihrem Angriff auf den Osten dienen." Eine Projektion dieses Gedankens auf die Vergangenheit kam 1938 mit dem Film „Aleksandr Nevskij" von Sergej Eisenstein auf die Leinwände der sowjetischen Kinos. Mit diesem Film zog Eisenstein eine geistige Verbindungslinie von der Eroberungspolitik des Deutschen Ordens im 13. und 14. Jahrhundert zur aggressiven Annexionspolitik von Hitlerdeutschland. Kurz vor dem Abschluß des Hitler-Stalin-Paktes wurde der Streifen aus dem Programm genommen, und Eisenstein inszenierte statt dessen am Moskauer Bolschoj-Theater Wagners „Walküre“. Nach dem deutschen Überfall auf die Sowjetunion am 22. Juni 1941 erschien Eisensteins Film hingegen geradezu prophetisch ${ }^{122}$.

Nach 1945 reduzierte die sowjetische Propaganda die Geschichte Ostpreußens und Königsbergs vollends auf seine militärische Rolle. Sie konnte dabei auf die Vorlagen und Interpretationen zurückgreifen, die deutsche Historiker während der Zeit des Nationalsozialismus hervorgebracht hatten. So hatte z. B. Götz von Selle noch 1944 in seiner „Geschichte der Albertus-Universität zu Königsberg in Preußen“ über die historische Mission Ostpreußens phantasiert: „Ewig jungfräulicher Boden ist dieser Osten. Generationen um Generationen sind aus dem Reich hierher gekommen und haben auf diesem Boden köstliches deutsches Gut erzeugt. Generationen um Generationen werden ferner aus diesem Reich kommen, und immer

121 Zitiert nach: Rürup, Berlin 1945, S. 59 f.

$122 \mathrm{Zu}$ den sowjetischen Filmen der Vorkriegs- und Kriegszeit vgl. Stites, Russian Popular Culture, S. 112-115. Zu Eisensteins Wagnerinszenierung vom Dezember 1939 vgl. Schlögel, Moskau, S. 303. Zu Hitlers Konzeption des Angriffes auf die Sowjetunion vgl. Ueberschär, Hitlers Entschluß zum „Lebensraum“-Krieg im Osten, S. 13-44. 
weiter wird sich das Land dehnen, bereichert um das, was in diesem neuen Osten entsteht." 123 Vor dem Hintergrund solcher Texte und den durchlittenen Erfahrungen des deutschen Überfalls auf die Sowjetunion mag es in russischen Ohren gar nicht so abstrus geklungen haben, wenn die sowjetische Propaganda die Gründung Ostpreußens durch den Deutschen Orden als einen geschichtlichen Konstruktionsfehler darstellte, der das Schicksal dieser Region für Jahrhunderte vorherbestimmte. Die „stumpfsinnigen“ preußischen Junker, so formulierte es 1947 die Kaliningradskaja Pravda, hätten „alle dunklen Seiten der deutschen Geschichte“ verkörpert: die „Gewalt, den Betrug und die unmäßige Eitelkeit“. Ihr Politik sei „eine Politik von Räubern ohne Traditionen“ gewesen, sie hätten an „sämtlichen damaligen Kriegen" teilgenommen. Königsberg war dieser Deutung zufolge der symbolträchtige Brennpunkt dieser permanenten Aggression: Die „preußischen Kurfürsten“ seien nicht ,in ihrer Hauptstadt Berlin, sondern ausgerechnet in Königsberg“ gekrönt worden ${ }^{124}$. Andere Aspekte der Stadtgeschichte, die noch in der Großen Sowjet-Enzyklopädie von 1936 erwähnt wurden, wie insbesondere die Lehrtätigkeit Immanuel Kants an der Königsberger Universität, blendete man im ersten Nachkriegsjahrzehnt völlig aus $^{125}$. Die Vorkriegsgeschichte Königsbergs wurde tabuisiert, und es durfte nur über die Abschnitte geredet werden, die zur Legitimation der Annexion der Stadt brauchbar waren. In diesem Zusammenhang bemühten sich sowjetische Veröffentlichungen um eine Anknüpfung an Stalins Diktum des „historisch gesehen slawischen Bodens“, den Ostpreußen darstelle. „Das Territorium Ostpreußens - urslawische Erde, die sich jahrhundertelang in Gefangenschaft befand - ist zu seinen wahren Herren zurückgekehrt. Die neuen Seiten der Geschichte dieses Gebietes werden von nun an und für immer nicht mehr leidvoll wie früher, sondern hell und freudebringend sein", begeisterte sich der Leiter der Gebietsverwaltung für Architektur, Dimitrij Tjan, im November 1947 in einem Artikel der Kaliningradskaja Pravda über das Ende ostpreußischen Sonderweges ${ }^{126}$. Im gleichen Jahr stellte der damalige Gebietsparteichef Vladimir Ščerbakov in seiner Broschüre über das „Stalin-Programm des wirtschaftlichen und kulturellen Aufbaus des Kaliningrader Gebietes“ fest: „Die sowjetische Armee hat für ewig die gefährlichste Heimstätte des Krieges und der Reaktion vernichtet und ausgelöscht [und] gab den Slawen ihren ureigenen Boden zurück. ,Der jahrhundertelange Kampf der slawischen Völker um ihre Existenz und ihre Unabhängigkeit ist mit dem Sieg über die deutschen Besatzer und deutschen Tyrannen zu Ende gebracht worden.‘ (J. Stalin, Über den Großen Vaterlän-

123 Zitiert nach: Hackmann, Königsberg in der deutschen Geschichtsschreibung, S. 472.

124 Kaliningradskaja Oblast', in: Kaliningradskaja Pravda, 17. November 1947. In Königsberg wurden seit 1701 die preußischen Könige gekrönt.

125 Vgl. Rier, Kenigsberg XII - načala XVI. Vekov.

126 Tjan, Sovetskij gorod Kaliningrad, in: Kaliningradskaja Pravda, 7. November 1947. 
dischen Krieg der Sowjetunion [...] “127 Ščerbakov ließ bewußt im unklaren, wer hier mit den „deutschen Besatzern" gemeint war. Während Stalin in seinem Text wohl ursprünglich in erster Linie die deutsche Wehrmacht im Blick hatte, die 1941 die Sowjetunion überfallen hatte, wird durch die Interpretation Ščrbakovs die gesamte deutsche Geschichte Ostpreußens als Besatzungszeit definiert.

Der recht unkonkrete Begriff des „urslawischen Bodens“ Ostpreußens war ein indirektes Eingeständnis der Tatsache, daß zumindest die Russen keinen historisch herleitbaren Anspruch auf das Gebiet vorbringen konnten. Doch auch die Pruzzen, die im 13. Jahrhundert vom Deutschen Orden unterworfen worden waren und von denen die "deutschen Ritter-Besatzer“ sich „sogar den eigenen Namen der Pruzzen“128 aneigneten, mußten zuerst zu Slawen umdefiniert werden, um den historischen Spagat vom hohen Mittelalter in das zwanzigste Jahrhundert zu vollbringen ${ }^{129}$. Anfang der fünfziger Jahre führten Mitarbeiter des Institutes für Geschichte der Akademie der Wissenschaften im Kaliningrader Gebiet Ausgrabungen durch, um Belege für die sowjetische Sicht der Geschichte zu finden. Triumphierend berichtete die Kaliningradskaja Pravda im Juli 1950 über die Untersuchungen: „Die während der Ausgrabungen gefundenen Gegenstände sind von hohem wissenschaftlichen Wert. Viele dieser Altertümer überführen die deutschen Geschichtswissenschaftler als Geschichtsfälscher. Völlig zerschlagen konnte man ihre pseudowissenschaftlichen Behauptungen darüber, daß angeblich die ersten Siedler auf dem Territorium Ostpreußens nicht Slawen, sondern Goten waren.“130 Auf Propagandaveranstaltungen wurde diese Interpretation der Geschichte den sowjetischen Übersiedlern nahegebracht, wie sich ein in Kaliningrad demobilisierter sowjetischer Soldat erinnerte: „Bis 1948, scheint mir, war bei allen ein Bestreben, sich von allem Fremden, Verhaßten, von allem Deutschen zu befreien. Auf den politischen Versammlungen wurde uns von Anfang an gesagt, daß hier das Land des preußischen Militarismus sei. Danach lehrten sie uns, daß vor langer Zeit hier slawisches Land war, das dann von den Deutschen okkupiert worden ist. " 131 Mit der Eroberung Königsbergs durch die Rote Armee, so betonten die neuen Machthaber deshalb immer wieder, sei „die historische Gerechtigkeit" wiederhergestellt worden ${ }^{132}$.

127 Ščerbakov, Stalinskaja Programma, S. 3 f.

128 Butovskaja, Kaliningrad. Illjustrirovannyj očerk, S. 8. Die Broschüre war der erste Stadtführer, der nach dem Krieg veröffentlicht wurde.

129 Beispiele der sowjetischen Geschichtsinterpretation der frühmittelalterlichen Vergangenheit des Gebietes sind: Percev, Prussija do eë zavoevanija nemcam, S. 47-51, und Grackij, Fašistskaja fal'sifikacija istorii, S. 134-145.

130 Kaliningradskaja Pravda, 26. Juli 1950, zitiert nach: Matthes, Als Russe in Ostpreußen, S. $255 \mathrm{f}$.

131 Erinnerung von Aleksandr Ignatevič Furmanov, in: Matthes, Als Russe in Ostpreußen, S. 255.

132 Zapadnyj forpost našej Rodiny, in: Kaliningradskaja Pravda, 2. November 1948. 
Die instrumentalisierende Umwertung der Geschichte war eine Methode, die sich auch hinsichtlich anderer annektierter Städten feststellen läßt, wie zum Beispiel im vergleichbaren Fall der finnischen Stadt Viipuri/Vyborg. Die 1293 von Torgil Knutsson zunächst als schwedische Grenzfestung gegründete Stadt, die 1403 die Stadtrechte erhielt, wurde während des Nordischen Krieges zwischen Schweden und Rußland (1700-1721) von den russischen Truppen im Jahr 1710 erobert und blieb bis zur Unabhängigkeit Finnlands nach der Oktoberrevolution Teil des Russischen Reiches. Nachdem die in der Zwischenkriegszeit zweitgrößte Stadt Finnlands bereits nach dem Ende des sowjetisch-finnischen Winterkrieges im März 1940 von der Sowjetunion annektiert worden war, wurde Vyborg - nach der durch Finnen und Deutsche im Zuge des Überfalles vom Juni 1941 durchgeführten zeitweiligen Rückeroberung - 1944 endgültig Teil der RSFSR ${ }^{133}$. Auch in diesem Fall wurden die Abschnitte der Stadtgeschichte, in denen der Ort Teil des schwedischen Königreiches oder der Republik Finnland war, als Besatzungszeit gewertet, nur daß diesmal die Karelier als frühgeschichtliches Stellvertretervolk fungierten ${ }^{134}$. Die schon bald nach dem Ende des Zweiten Weltkrieges eintretende Entspannung der Beziehungen Finnlands zur Sowjetunion wirkte sich jedoch auch auf die Bewertung der schwedischen bzw. finnischen Geschichte Vyborgs aus: Im Unterschied zur Vorgehensweise in Kaliningrad wurden diese Abschnitte der Geschichte Vyborgs nicht gänzlich auf den Aspekt der Besatzung reduziert - so ging zum Beispiel Ende der fünfziger Jahre eine Veröffentlichung zur Stadtgeschichte Vyborgs auch auf die wirtschaftliche Rolle des Hafens in schwedischer und finnischer Zeit und auf Details wie die mittelalterliche Gildenverfassung der Stadt ein ${ }^{135}$.

\section{Vom Wert der deutschen Architektur}

Die instrumentalisierte Interpretation der Geschichte Königsbergs hatte im ersten Nachkriegsjahrzehnt einen entscheidenden Einfluß auf die Konzeption der Wiederaufbauplanung, denn nach Ansicht der sowjetischen Propaganda manifestierte sich in der Vorkriegsarchitektur Kaliningrads die feind-

133 Erstmals wurde Vüpuri gemäß dem Moskauer Friedensvertrag zwischen der Sowjetunion und Finnland vom März 1940 an die Sowjetunion übergeben. Nach dem deutschen Überfall auf die Sowjetunion, an dem sich auch Finnland als Verbündeter Deutschlands beteiligte, kam die Stadt zwischen 1941 und 1944 wieder unter finnische Hoheit. Vgl. Tilli, Takaisin Viipurin Kohtalonruodet, und Neuvonen, Viipurin Historiallinen Keskusta, S. 18-25 und $98 \mathrm{f}$.

134 Vgl. M.V. Vasil'ev, Vyborg, Leningrad 1958, S. 3-62.

135 Ebenda. Allerdings muß angemerkt werden, daß sowjetische Forscher aufgrund der Evakuierung des Königsberger Staatsarchivs und der Vernichtung der Universtiätsbibliothek kaum Material für Forschungen gefunden hätten, während zu Vyborgs Geschichte im Mittelalter bereits von russischen Historikern geforscht worden war, als diese Stadt noch zum zum russischen Zarenreich gehörte. 
liche deutsche Geschichte der Stadt. Schon aus der Definition der deutschen Vergangenheit als Besatzungszeit mußte sich eine direkte Schlußfolgerung für die Bewertung der Architektur und des Städtebaus der deutschen Zeit ergeben: Da ein Besatzungsregime zwangsläufig nur etwas Vorübergehendes - und in diesem Falle zudem etwas Unrechtmäßiges - darstellt, so sind auch die Eingriffe eines solchen Regimes nur als vorübergehend - und unrechtmäßig - zu betrachten. Demzufolge war die Architektur aus deutscher Zeit ein nur temporäres Phänomen, eine Hinterlassenschaft von Besatzern ohne eigenständigen Wert. Ende 1947 sprach daher Dimitrij Tjan, der bis zur Schaffung des Amtes des Chefarchitekten der Stadt Kaliningrad die Hauptverantwortung für den Wiederaufbau trug, in einer Analyse der deutschen Architektur in Ostpreußen den Städten des Kaliningrader Gebietes jegliche städtebauliche Qualität ab. Diese hätten sich „planlos, abhängig von der historischen Etappe, stark diesen oder jenen herrschenden Gesellschaftsaufbau widerspiegelnd“ entwickelt. Es sei „unmöglich [...], im Verlauf der Straßen bestimmte, geometrische Prinzipien zu finden. Viele Planungsgebiete sind untereinander nicht verbunden. [...] In architektonischer Hinsicht ist es schwierig, in den Städten des Gebietes abgeschlossene Ensembles, Plätze oder Baugruppen zu finden, mit Ausnahme einiger Viertel, die Ende des 19. Jahrhunderts oder in den 30er Jahren des 20. Jahrhunderts entstanden sind. Die Architektur der Gebäude befindet sich auf einem niedrigen Niveau. Die vorherrschenden Stile sind die Gotik, die modernisierte Gotik [Nengotik] und die Gotik im Konstruktivismus [Expressionismus ${ }^{136}$. Charakteristisches Merkmal aller Städte ist, daß sie nicht architektonisch geplant, sondern [nach] technisch[en Prinzipien] geschaffen wurden. Organische, architektonische Mängel sind durch Ordnung und die

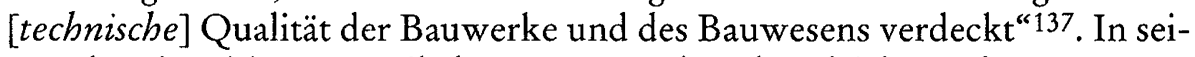
nem bereits zitierten Artikel vom November des gleichen Jahres ergänzte er: „Der vorherrschende Stil [Königsbergs] war eine simplifizierte Gotik, oder richtiger - eine gotische Verkleidung. Das reichliche Grün hat in den Sommermonaten die Häßlichkeit dieser Bauten verdeckt." 138

Ausschlaggebend für die negative Bewertung der deutschen Architektur war aber weniger ihre vermeintliche, generelle Minderwertigkeit - wichtiger war, daß die bestehenden deutschen Gebäude, wie der anfangs zitierte Pravda-Artikel vom 13. April 1945 belegt, als Monumente der Aggression gegen die östlichen Nachbarn Ostpreußens betrachtet wurden. Die ideologische Frontstellung der Bauten des ehemaligen Königsberg hob Dimitrij Navalichin, von 1948 bis 1955 erster Chefarchitekt von Kaliningrad und danach bis 1957 Chef der Gebietsverwaltung für Architektur, noch Mitte der fünf-

136 Hier hatte Tjan wahrscheinlich das von Hans Hopp errichtete „Haus der Technil" auf dem

Gelände der Ostmesse und das Stadthaus gegenüber dem Nordbahnhof im Auge.

137 GAKO, f. 520, op. 1, d. 12, 1. 1 f.

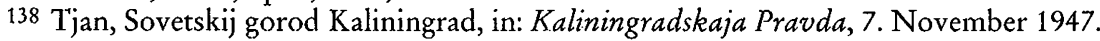


ziger Jahre hervor. Er betonte insbesondere die Dominanz der Militärbauten im Zentrum, die „sich aus ihrer vorteilhaften Schlüssellage im Ort und ihrer charakteristischenVerteilung erklärt, die ein bestimmtes [opredelennuju] System darstellt, das scharf zur allgemeinen Systemlosigkeit der Wohnviertel kontrastiert. [...] Die Sättigung des Stadtzentrums und auch der übrigen Viertel der Stadt mit Kriegsbauten prägte die Architektur einer Reihe anderer Gebäude stark und drückte der ganzen Stadt einen spezifischen. Kasernenanblick auf.“ Den militaristischen Charakter der Stadt machte er besonders in den Arbeitervierteln des ehemaligen Königsbergs fest. Diese waren seiner Meinung nach „durch eine äußerste Primitivität der planerischen und architektonischen Lösungen " geprägt, so daß Arbeiterhäuser optisch „in trostlose, freudlose Kasernen“ umgewandelt worden seien. Zivile Gebäude hätten unter den Bedingungen einer militarisierten Stadt nur eine „untergeordnete Bedeutung“ besessen. Aus dieser Analyse zog Navalichin ein ebenso vernichtendes wie ideologisch überhöhtes Urteil: Der so entstandene architektonische Anblick des ehemaligen Königsberg beinhalte „neben den für privatkapitalistische Städte typischen eigentümlichen, historisch entwickelten Merkmalen die eigenartigen Züge der deutschen kriegs-militaristischen Stadt, die Ideen und Vorstellungen propagiert und bekräftigt, die der Menschheit verhaßt sind“139.

Die Verwendung Königsbergs als Kulisse für sowjetische Spielfilme setzte diese Interpretation der Stadt als Verkörperung des preußischen Militarismus in Bilder um: Königsberg wird in diesen Filmen zu einer idealtypischen deutschen, also feindlichen Stadt abstrahiert. Als einer der ersten Filme wurde 1948 „Begegnung an der Elbe“ in Kaliningrad gedreht, in dem die Stadt für das von Amerikanern und Sowjets besetzte Torgau steht. Durch den im Film „Altenburg“ genannten Ort schleichen zahlreiche untergetauchte Nazis und Spione, die vor den bedrohlichen Ruinen Königsbergs, vor spitzen Türmen und ausgestorbenen Straßen, wirkungsvoll in Szene gesetzt wurden und so den Geist, der von diesen Ruinen ausging, visualisierten. Was diesen Film besonders bemerkenswert macht, ist die Tatsache, daß die Filmstadt Altenburg aus den Orten Königsberg und Riga zusammengesetzt wurde. Tatsächlich hatte man auch im baltischen Nachbarland nach 1945 ernste Probleme mit dem architektonischen Erbe: Noch im April 1954 erklärte die lettische Akademie der Wissenschaften, daß die Bebauung der Altstadt Rigas von deutschen Besatzern stamme und deshalb dem nationalen Erbe widerspreche ${ }^{140}$. Dieses Ineinanderverschmelzen der beiden Städte verdeutlicht in besonderer Weise, daß Königsberg nicht als realer Ort, sondern als eine feindliche Idee gesehen wurde. Die Verwendung der Stadt als namenlose Kulisse wurde noch gesteigert, als 1959 die neugotischen Bastio-

139 Navalichin, K voprosu rekonstrukcii centra goroda Kaliningrada, Bd. I, S. 26-33 und 167. 140 Vgl. Bogdanov, Voprosy rekonstrukcii centrov gorodov pribaltiki, S. 61-80, hier: S. 61. 
nen der Königsberger Stadtbefestigung in dem Film „Ein Menschenschicksal“ (,Sudba čeloveka“) unter anderem als Gebäude des Vernichtungslagers Auschwitz auftauchen.

\section{Dem neuen Menschen eine neue Stadt}

\section{Die Gefabr der Rekonstruktion}

Aus den Bewertungen der baulichen Hinterlassenschaften der Deutschen ergab sich für die sowjetischen Planer eine klare Handlungsanweisung: Die neue Gesellschaft, der neue Staat brauchte eine neue Architektur. „Völlig abgeworfen" werden sollte "der deutsche [architektonische] Standard, der beim russischen Menschen Verzagtheit verursacht"141. Dimitrij Tjan, der laut Kaliningradskaja Pravda "klar den tief sozialen Sinn" 142 seines planerischen Schaffens erkannte, sah deshalb im November 1947 eine der vorrangigen Aufgaben des Wiederaufbaus in der Schaffung neuer Generalpläne für die Städte des Kaliningrader Gebietes. Dies bewertete er jedoch als „keine leichte Aufgabe, denn die Architektur der deutschen Städte ist der sowjetischen Baukunst von der Form her fremd und im Inhalt unannehmbar". Der „deutsch-teutonische Stil“ des Städtebaus, so betonte er, sei „ein Überbleibsel der Zeit, in der die deutschen Feudalherren Schlösser und Bastionen errichtet haben. In diesem Stil haben sich bis in unsere Tage die architektonischen Prinzipien des Mittelalters erhalten. Unsere Architektur jedoch basiert auf den Prinzipien der neuen, sozialistischen Ära der Entwicklung der menschlichen Gesellschaft." Wichtigste Aufgabe der neuen Generalpläne sei es daher, „die neue sozio-ökonomische Struktur“ der Städte zum Ausdruck zu bringen ${ }^{143}$. Den Kontrast zwischen deutschen und sowjetischen Städten hob auch Navalichin im Mai 1948 in seiner ersten Veröffentlichung als Chefarchitekt Kaliningrads hervor: „In die durch Luftangriffe und Artilleriefeuer zerstörte, kapitalistische Stadt ist unser sowjetischer Mensch gekommen - der Sieger und Schöpfer, der Mensch einer neuen progressiven und führenden Kultur. [...] Die Anforderungen, die unser sowjetischer Mensch an seine sozialistische Stadt stellt, sind bedeutend höher als die Prinzipien der Planung und Normen, die in kapitalistischen Ländern gelten." 144 Ein Jahr später sprach er den Kaliningradern für den Wiederaufbau Mut zu: „Der Wiederaufbau jeder Stadt, die während des Krieges zerstört wurde, ist schwierig. Für die Kaliningrader, die eine sowjetische Stadt

141 Stroiteli, in: Kaliningradskaja Pravda, 1. Mai 1948.

142 Ebenda.

143 Tjan, Sovetskij gorod Kaliningrad.

144 Navalichin, Na razvalinach Kenigsberga postroim socialističeskij Kaliningrad, in: Kaliningradskaja Pravda, 15. Mai 1948. 
auf den Ruinen der Zitadelle des preußischen Militarismus bauen, verdoppeln sich diese Schwierigkeiten noch. Denn eine sozialistische Stadt unterscheidet sich wie Tag und Nacht von den finsteren und mißgestalteten deutschen Städten. Doch welche dankbare, große Aufgabe steht dafür vor uns!" 145 In den Augen der Zeitgenossen wurde die Architektur somit zum Sinnbild des gesellschaftlichen Wandels: Den „schiefen, engen“ Gassen der mittelalterlichen Altstadt Königsbergs wurden in der Kaliningradskaja Pravda die geplanten „wunderbaren hellen“ Gebäude der neuen Zeit entgegengestellt, die an breiten und geraden Prospekten errichtet werden sollten ${ }^{146}$.

Gewunden und klein gegen gewaltig und gradlinig: In diesem Gegensatzpaar sollte sich die kulturelle Frontstellung als Gegensatz zwischen dem veralteten, weil irrationalen Deutschtum und der wissenschaftlichen Weltanschauung des sowjetischen Sozialismus zeigen ${ }^{147}$. Die Auslöschung der überkommenen Bebauung wurde somit auch als ein Akt der politischen Hygiene angesehen. In Kaliningrad war also wenig von der Interpretationswende zu bemerken, die die offizielle sowjetische Geschichtswissenschaft nach 1945 vollzog: Dieser neuen Auslegung zufolge war der Zweite Weltkrieg nicht ein Kampf zweier Völker, wie dies bislang behauptet worden war, sondern ein Kampf zweier vorrangig politischer Regime, den der Sozialismus dank der Führung der bolschewistischen Partei gewonnen habe ${ }^{148}$.

$\mathrm{Da}$ in Kaliningrad die kulturelle Frontstellung beibehalten wurde, sah man in der Wiederherstellung deutscher Gebäude eine Gefahr: Die sich in eine „russisch-sowjetische Stadt verwandelnde ehemals deutsche Stadt Königsberg kann und darf nicht im ursprünglichen Zustand wiederaufgebaut werden“, mahnte Navalichin noch in den fünfziger Jahren als Folgerung aus seiner Analyse der Vorkriegsbebauung ${ }^{149}$. Schon im Juli 1947 hatte eine Bauingenieurin in der Kaliningradskaja Pravda gefordert, Kaliningrad müsse „im Geiste der sowjetischen Ideologie“ wiederaufgebaut werden, um

145 Navalichin, Každoe novoe zdanie dol'žno ukrašat naš gorod, in: Kaliningradskaja Pravda, 3. September 1949.

$146 \mathrm{Ju}$. Cygankov, Iz prošlogo. Kenigsbergskij zamok, in: Kaliningradskaja Pravda, 31. Mai 1953.

147 Die radikale Abkehr der sowjetischen Planer von der alten Stadt hatte neben der Frontstellung gegen die deutsche Kultur aber auch innersowjetische Gründe. Churchills Diktum "A desaster, but an opportunity" galt in der Nachkriegszeit auch in der Sowjetunion: Zerstörungen der sowjetischen Städte wurden als Möglichkeit gesehen, „die früheren Planungs- und Baumängel radikal zu beseitigen“, wie der Architekt Karo. S. Alabjan 1943 in einem Artikel über den Wiederaufbau Stalingrads schrieb (Alabjan, Kontury budeščego Stalingrada, S. 78). Vgl. dazu: Day, Building Socialism, Kapitel 4: Stalingrad, rebuilt and unbuilt. 1943-1949, bes. S. 70-73.

148 Vgl. dazu: Gallagher, Soviet History of World War II.

149 Navalichin, K voprosu rekonstrukcii centra goroda Kaliningrada, Bd. 1, S. 33. 
auf diese Weise den „preußischen Geist der Stadt auszumerzen“150. Drei Monate später ergänzte sie im gleichen Blatt, es sei gar keine Frage, „daß wir die Gebäude nicht sklavisch so kopieren können, wie sie vor ihrer Zerstörung gewesen sind. Wir sind verpflichtet, auf eine neue, sowjetische Art zu bauen, in Übereinstimmung mit den gewachsenen kulturellen Bedürfnissen unseres Volkes"151.

Hintergrund für dieses vehemente Eintreten für eine Umarbeitung auch einzelner Gebäude war die Befürchtung, daß die deutsche Architektur einen schlechten Einfluß auf die sowjetischen Menschen haben könnte - wurde doch die Architektur in der Sowjetunion als Erziehungsmittel der Bevölkerung betrachtet ${ }^{152}$. So meinte nach dem Ende des Krieges der Vorsitzende des Staatlichen Komitees für architektonische Angelegenheiten, Arkadij Mordvinov, die neu zu errichtenden Gebäude müßten die „Prinzipien der Schönheit in das Alltagsleben der Menschen einführen“, andernfalls wären sie bar jedes „symbolischen Inhaltes“, also ohne politische Aussage ${ }^{153}$. Der Kritiker A. Michajlov formulierte die Forderung nach der propagandistischen Instrumentalisierung der Baukunst noch deutlicher, als er im April 1945 darauf hinwies, daß die Nachkriegsarchitektur den „Geist der Epoche widerspiegeln" müsse ${ }^{154}$.

Aufgrund der Bedeutung, die offizielle Stellen in der Sowjetunion dem politisch-symbolischen Gehalt von Gebäuden beimaßen, kann somit die Forderung, Kaliningrad „im Geiste der sowjetischen Ideologie“ wiederaufzubauen, auch als präventive Maßnahme gesehen werden, um keinen politisch mißliebigen Weltanschauungen Vorschub zu leisten oder sie überhaupt entstehen zu lassen. Noch in den fünfziger Jahren stieß daher der Wiederaufbau von Gebäuden „in ihrem ursprünglichen, unter den Deutschen bestehenden Zustand" auf die scharfe Kritik Navalichins, da er in diesen Häusern „dem sowjetischen Menschen fremde Elemente der deutschen kapitalistischen Stadt"155 sah. Die in seinen Augen hier lauernde Gefähr-

150 N. Dychovičnaja, Neotložnie voprosy vosstanovlenii i planirovki Kaliningrada, in: Kaliningradskaja Pravda, 30. Juli 1947.

151 N. Dychovičnaja, Stroit' po-novomu, po-sovetski, in: Kaliningradskaja Pravda, 9. Oktober 1947.

152 Vgl. Navalichin, K voprosu rekonstrukcii goroda Kaliningrada, Bd. 1, S. 164

153 Arkadij Mordvinov, Chudožestvennye problemy sovetskoj architektury, in: ders., Architektura. Sbornik statej po tvorčeskim voprosam, Moskau 1945, S. 3-23, zitiert nach: Day, Building Socialism, S. 76.

154 Michajlov äußerte sich zu diesem Punkt auf einem Forum der Union der Sowjetischen Architekten (SSA), auf der über „Neue Entwicklungen in der Architektur“ gesprochen wurde. Seine Äußerungen waren eigentlich gegen die Vertreter des Konstruktivismus gerichtet, die seiner Meinung nach nicht verstanden, daß der Sieg gegen die Deutschen eine repräsentative Architektur erfordere. Seine Aussage über die politische Funktion von Architektur läßt sich jedoch auch auf den Fall Kaliningrad anwenden. Zitiert nach: Day, Building Socialism, S. $74 \mathrm{f}$.

155 Navalichin, $K$ voprosu rekonstrukcii centra goroda Kaliningrada, Bd. 1, S. 110. Schon am 3. September 1949 schrieb Navalichin in dem Artikel "Každoe novoe zdanie dol'žno ukra- 


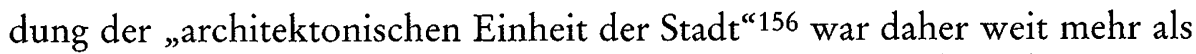
nur ein ästhetisches Problem - sie symbolisierte die Gefährdung der Homogenität der Gesellschaft durch fremde Ideologien.

Mit seiner Auffassung war Navalichin jedoch nicht gänzlich unumstritten. Schon auf der ersten „Allgemeinen Versammlung der Architekten der Stadt Kaliningrad" am 8. September 1948 wandte einer der Anwesenden ein: „Die vollständige Änderung des ,preußischen Gesichtes der Stadt', von der hier die Rede ist, ist eine kaum bemerkbare, unwirksame und zudem unmögliche Methode." 157 Die hier zutage tretende Auseinandersetzung um die Umgestaltung der Fassaden beim Wiederaufbau wurde zwischen Pragmatikern, denen es in erster Linie auf die rasche Schaffung von Wohnraum ankam, und Planern, die sich mehr von ideologischen Überlegungen leiten ließen, ausgetragen. Obwohl durch diesen Konflikt schon früh die engen wirtschaftlichen Grenzen der Umgestaltung Königsbergs herausgearbeitet wurden, zog sich der Streit noch bis in die sechziger Jahre hin, ohne daß eine Seite sich völlig durchsetzen konnte. Der Hinweis des Kaliningrader Chefarchitekten von 1949, daß laut eines Erlasses der sowjetischen Regierung keine Häuser ohne (klassizistische) Stukkatierung neu errichtet oder wiederaufgebaut werden dürften, wurde regelmäßig mißachtet ${ }^{158}$. Noch Mitte der fünfziger Jahre forderte Navalichin, in „einzelnen Fällen, wenn der Wiederaufbau eines Gebäudes unumgänglich ist, es aber wegen ästhetischer Erwägungen“ nicht im früheren Zustand gelassen werden könne, „den fremden architektonischen Einfluß solcher Bauten" durch eine Überarbeitung der Fassade abzuschwächen ${ }^{159}$. Einige Jahre lang mußten dem Chefarchitekten deshalb alle Wiederaufbauprojekte zur Genehmigung vorgelegt werden, damit er die Fassadengestaltung kontrollieren konnte ${ }^{160}$. Trotzdem wurden insbesondere viele sachlich gestaltete Bauten der zwanziger Jahre ohne wesentliche Veränderungen im ursprünglichen Zustand wiederhergerichtet, wie zum Beispiel das ehemalige Parkhotel am Schloß-/Unterteich, für das bereits ein Fassadenentwurf mit Pilastern und ausladenden Kranzgesimsen vorlag 161 .

šat' naš gorod“ in der Kaliningradskaja Pravda: „Der uns verhaßte preußische Geist, der noch in den äußeren Konturen einiger Viertel erhalten ist, wird endgültig ausgelöscht. Danach streben wir, daran arbeiten die Kaliningrader beharrlich."

156 Navalichin, K voprosu rekonstrukcii centra goroda Kaliningrada, S. 77. Als Beispiele führt er unter anderem den ehemaligen Hauptbahnhof (heute Südbahnhof) und das Parkhotel am Schloß-/Unterteich an.

157 GAKO, f. 522, op. 1, d. 3, 1. 2.

158 Dimitrij Navalichin, Každoe zdanie dol'žno ukrašat' naš gorod, in: Kaliningradskaja Pravda, 3. September 1949.

159 Navalichin, K voprosu rekonstrukcija centra goroda Kaliningrada, Bd. 1, S. 69.

160 Vgl. zum Beispiel: GAKO, f. 522, op. 1, d. 8. Die Akte enhält etwa 80 Einzelprojekte aus der ersten Hälfte der fünfziger Jahre, die alle von Navalichin gegengezeichnet worden sind.

161 Auch in Vyborg sollte die berühmte Stadtbibliothek von Alvar Aalto, die 1933-1935 errichtet worden war, in den 50er Jahren mit einer neoklassizistischen Stuckfassade versehen wer- 
Wie erfolglos das Bemühen um die Neugestaltung von Altbauten war, weil dieses Problem unterhalb der Ebene der Planer und der hohen Funktionäre offensichtlich häufig als drittrangig angesehen wurde, zeigt schon allein der laxe Umgang mit den alten deutschen Inschriften. Deren Entfernung wurde an der Basis offensichtlich nicht mit dem Nachdruck verfolgt, den sich das Gebietskomitee der Partei wünschte, das sich im Mai 1952 in einem Erlaß beklagte: „In den Städten und Rayons des Gebietes haben sich an einzelnen Wohngebäuden, an Gebäuden von sozial-kommunalen Unternehmen, Industriebetrieben und Werkstätten, an Eisenbahnstationen und besonders an zerstörten Gebäuden alte Inschriften, Firmenschilder, Reklame deutscher Unternehmen und Hinweisschilder in deutscher Sprache erhalten. An manchen Orten sind bis heute nicht einmal die Inschriften antisowjetischen Charakters ausgelöscht worden. [...] Ungeachtet dessen, daß das Kaliningrader Gebiet schon sechs Jahre besteht, haben die Rayonskomitees und die Stadtkomitees der VKP, die Rayonsexekutivkomitees und die Leiter der Unternehmen und Verwaltungen bis heute keine Maßnahmen ergriffen, um die der Bevölkerung fremden alten deutschen Inschriften $\mathrm{zu}$ beseitigen, und messen dieser Maßnahme in vielen Fällen auch keine Bedeutung bei." 162

\section{Konzeptionen für das Zentrum}

Ähnliche Auseinandersetzungen wie die um die deutsche Architektur wurden in Kaliningrad auf dem Gebiet der Stadtplanung ausgefochten: Angesichts der allgemeinen Geringschätzung von Architektur und Städtebau des alten Königsberger Stadtzentrums und vor allem aufgrund der enormen Zerstörungen in diesem Gebiet erschien es vielen Neuankömmlingen fraglich, ob der Wiederaufbau des Zentrums überhaupt sinnvoll sei. In seinem ersten Bericht vom Juni 1946 „Über die Frage des Wiederaufbaus und der Rekonstruktion der Stadt Königsberg" für den Chef der Zivilverwaltung des Königsberger Gebietes, Vasilij A. Borisov, vertrat der Chefarchitekt der Gebietskommunalwirtschaft, P. V. Timochin, die Ansicht, das Zentrum sei

den, was jedoch - wie bei den meisten Bauten der Klassischen Moderne in Kaliningrad, unterblieb. (Zur Bibliothek und seiner Geschichte nach dem Beginn des Zweiten Weltkrieges bis 1992 vgl. Spens, Viipuri Library.) Das Bestreben, konstruktivistische Gebäude mit einer Stuckfassade umzugestalten, hatte seine Ursache jedoch nicht nur in der kulturellen Auseinandersetzung mit den besetzten Städten, sondern läßt sich auch auf innersowjetische Kämpfe um die Richtung der Architektur seit Anfang der 30er Jahre zurückführen. Nachdem der Ncoklassizismus als verbindlicher Stil festgeschrieben worden war, sind in vielen Städten der Sowjetunion konstruktivistische Bauten mit Stuckfassaden versehen worden. Vgl. dazu: Day, Building Socialism, S. $41 \mathrm{f}$.

162 CChIDNIKO, f. 1, op. 11, d. 17, 1. 109 f., Protokoll des Kaliningrader Gebietsparteikomitees No. 129, vom 30. Mai 1952, Punkt 25: „Über die Entfernung alter Inschriften und Hinweisschilder in deutscher Sprache an Gebäuden, Zäunen und anderen Bauwerken und an Wegen." 
so stark zerstört, „daß es kaum für den Wiederaufbau vorgesehen sein wird, und wenn doch die Notwendigkeit seines Wiederaufbaues entsteht, dieser mehr als zehn Jahre dauern wird“. Seiner Ansicht nach sollte „das ehemalige Stadtzentrum so gelassen werden [...], wie es jetzt ist, um es als Denkmal des Sieges im Großen Vaterländischen Krieg 1941-1945 über den deutschen Faschismus zu erhalten "163. In seiner Radikalität fand dieser Vorschlag, die Altstadt zu einem Freilichtmuseum zu machen, zwar nicht allzu viele Befürworter, doch wurde in der unmittelbaren Nachkriegszeit aufgrund der Zerstörung der Innenstadt ernsthaft erwogen, den alten Stadtkern innerhalb der Befestigungsanlagen des 19. Jahrhunderts zumindest vorerst bewußt brachliegen zu lassen. Das Zentrum des neuen Kaliningrad sollte provisorisch in der Gegend des Nordbahnhofes oder, wie Timochin vorschlug, auf dem Gelände der abgebrannten Ostmesse neu entstehen ${ }^{164}$. Ein anderer Vorschlag bestand darin, das Zentrum anstelle der Befestigungsanlagen kreisförmig entlang einer Ringstraße um den alten Stadtkern herumzulegen. Die „tote Zone“ der Altstadt sollte hierbei von der neuen Stadt durch einen Grünstreifen - gewissermaßen einen cordon sanitaire - getrennt werden. Das ehemalige Zentrum zwischen Nord- und Südbahnhof war nach diesen beiden Vorschlägen als städtebauliche Reserve vorgesehen, falls in ferner Zukunft neue Wohngebiete gebraucht würden ${ }^{165}$. Die Idee, den alten Stadtkern als Freilichtmuseum des Sieges über Deutschland im Zustand von 1945 zu belassen, war trotzdem noch nicht endgültig vom Tisch: Da der alte Stadtkern vorläufig nicht verwendbar erschien, tauchte dieser Vorschlag Anfang der fünfziger Jahre noch einmal auf ${ }^{166}$.

Die meisten sowjetischen Planer wollten das alte Zentrum hingegen nicht aufgeben. $\mathrm{Zu}$ einer Entscheidung dieser Frage kam es aber erst Ende der vierziger Jahre, als der erste Generalplan für Kaliningrad ausgearbeitet wurde. In diesem Dokument sollten für die folgenden 20 Jahre die städtebauliche Entwicklung, Art, Ausmaß und Lage der Bebauung, Flächen für Verwaltung, Handel, Industrie, Wohnen und Erholung und die Verkehrsund Versorgungsinfrastruktur festgelegt werden. Am 13. Mai 1948 beauftragte der Chef der Verwaltung für Architektur beim Ministerrat der RSFSR, V. Škvarikov, den Direktor des Moskauer Staatlichen Institutes für die Projektierung von Städten (Giprogor), N. Ja. Burlakov, mit der Ausar-

163 GAKO, f. 520, op. 1, d. 2, 1. 1f. Hervorhebung im Original. Als nach der Befreiung Warschaus die Planung des Wiederaufbaus der polnischen Hauptstadt begann, gab es auch dort Stimmen, die die Rekonstruktion der Altstadt ablehnten - allerdings aus völlig anderen Motiven: K. Vyka machte den Vorschlag, die Altstadt als Freilichtmuseum zu belassen, um die nationalsozialistische Barbarei zu dokumentieren, und eine moderne Straße um das alte Zentrum herumzubauen, von der aus Touristen die Ruinen betrachten könnten. Vgl. Predtečenskij, Vosstanovlenie starich gorodskich centrov, S. 226-271, hier: S. 227-229.

164 Zu Timochin: GAKO, f. 520, op. 1, d. 2, 1. 1 f.

$165 \mathrm{Vgl}$. Navalichin, K voprosu rekonstrukcija centra goroda Kaliningrada, Bd. 1, S. 94-96.

166 Vgl. Na zapade - net bolše vostočnoj prussii, S. 3-14, hier: S. 14. 
beitung eines Generalplanes für Kaliningrad ${ }^{167}$. Auf diese Beauftragung hatte man in Kaliningrad schon ungeduldig gewartet: Nachdem über ein Jahr seit der formalen Annexion Kaliningrads vergangen war, ohne daß die Wiederaufbauplanungen in Gang gekommen waren, hatte sich im Mai 1947 der Parteichef von Kaliningrad, P. Koločov, in dieser Sache an den Kaliningrader Gebietsparteichef gewandt. Dieser sollte sich beim Ministerrat der UdSSR für die Ausarbeitung eines Generalplanes für Kaliningrad einsetzen $^{168}$. Bis der entsprechende Auftrag ein Jahr später endlich an Giprogor erging, blühten die Gerüchte. So meldete die Kaliningradskaja Pravda am 1. Mai 1948 voreilig, daß sich der berühmte Architekt des Leninmausoleums, Aleksej V. Sčusev, bereits mit dem Kaliningrader Generalplan beschäftige ${ }^{169}$. Tatsächlich arbeitete Ščusev aber bereits seit längerem am Wiederaufbau von Novgorod und Stalingrad 170 .

Infolge der Zentralisierung der Wiederaufbauplanung konnten die lokalen bzw. regionalen Autoritäten nicht eigenmächtig über den zukünftigen Generalplan entscheiden: Um die Wiederaufbauverwaltung zu straffen, eine stärkere Kontrolle über den Städtebau in der Sowjetunion zu erlangen und besonders die Priorität der politisch-symbolischen Zielsetzung der Architektur sicherzustellen, war am 30. September 1943 das Staatliche Komitee für Architektonische Angelegenheiten beim Ministerrat der UdSSR gegründet worden. Auf Ebene der Republiken wurde das Komitee von den Verwaltungen für Architektur vertreten; die Verwaltung für Architektur beim Ministerrat der RSFSR unter V. Škvarikov wurde am 21. Dezember 1943 gegründet ${ }^{171}$. Sie trat in den folgenden Jahren beim Wiederaufbau als Auftraggeber stellvertretend für den Ministerrat auf und hatte somit maßgeblichen Einfluß auf die Planung.

Der erste Entwurf des Generalplanes, den die Mitarbeiter von Giprogor im Frühjahr 1949 vorlegten, folgte denn auch weitgehend den Vorstellungen der Verwaltung für Architektur. Die Behörde legte besonderen Wert auf die Ausarbeitung von Projekten für Stadtzentren, weil deren symbolischer Wert als Schlüssel für den sozialistischen Um- und Wiederaufbau der sowjetischen Städte gesehen wurde ${ }^{172}$. Folglich beschäftigten sich die Architekten von Giprogor zu einem wesentlichen Teil mit der Frage der Unterbringung des Zentrums, über die in Kaliningrad bis zu diesem Zeitpunkt noch keine Entscheidung getroffen worden war. In einem Artikel für die Kaliningrads-

167 GAKO, f. 520, op. 1, d. 8, 1. 1, Befehl No. 195 des Chefs der Verwaltung für Architektur beim Ministerrat der RSFSR, Skvarikov.

168 CChIDNIKO, f. 2, op. 1, d. 22, 1. 20-25, hier: 1. 25, Kopie des Briefs des Ersten Sekretärs des Kaliningrader Stadtparteikomitees, P. Koločov, an den Ersten Sekretär des Kaliningrader Gebietsparteikomitees, Jurij P. Ivanov, vom Mai 1947 [ohne genaues Datum].

169 Stroiteli, in: Kaliningradskaja Pravda, 1. Mai 1948.

170 Vgl. Ščusev, Generalnyj plan Novgoroda, S. 3-10.

171 Vgl. Belov, Podnjatie iz ruin, S. $47 \mathrm{f}$.

172 Vgl. Day, Building Socialism, S. 76. 
kaja Pravda sprach sich der Leiter des Giprogor-Projektes, M. R. Naumov, am 30. April 1949 eindeutig gegen die Verlagerung des Zentrums an die Peripherie aus. Allerdings führte er an erster Stelle pragmatische Gründe für seine Entscheidung an: Im Zentrum träfen die Verkehrsverbindungen zwischen den Außenbezirken aufeinander, in diesem Bereich gäbe es wiederaufbaufähige Gebäude, und schließlich seien die unterirdischen Versorgungsleitungen noch zu verwenden. Auf dieser Entscheidung aufbauend, entwickelten die Mitarbeiter von Giprogor einen Wiederaufbauplan für das Zentrum, der der Forderung nach Repräsentativität der Architektur Rechnung trug. Den Kern ihrer Konzeption bildeten die Verbreiterung und Begradigung von Straßen und die Errichtung eines großen Palastes der Sowjets anstelle des Schlosses: „Das große Gebäude des Sowjetpalastes soll ein Denkmal für Michail Ivanovič Kalinin sein, den großen Aktivisten der Kommunistischen Partei und des sowjetischen Staates. Der Palast soll gekrönt sein von einem hohen, schon von fern sichtbaren Leuchtturm, der den Charakter der Stadt Kaliningrad als Hafenstadt unterstreichen soll. Die Schaffung des künftigen Palastes ist die Aufgabe unserer sowjetischen Architekten, die ein Projekt ausarbeiten sollen, das des neuen Kaliningrad würdig ist." 173

Bei anderen Planern stand der Gedanke der Repräsentativität bei der Frage nach Lage und Gestaltung des neuen Stadtzentrums stärker im Vordergrund. Der Kaliningrader Chefarchitekt Navalichin traf seine Entscheidung über die Plazierung des Zentrums bei einem Blick auf den Stadtplan: Er entschied sich in erster Linie gegen dessen Verlagerung in einen der Vororte, da dies die Realisierung eines „genügend ausdrucksstarken allgemeinen kompositorischen Stadtentwurfes" blockiert hätte174 - ein schwarzes Loch im geographischen Mittelpunkt des sozialistischen Kaliningrad wollte er verhindern. Der Leiter der Gebietsverwaltung für Architektur, Dimitrij Tjan, machte sich in erster Linie Gedanken über die Außenwirkung der neuen Stadt: Für ihn stand bereits Ende 1947 fest, daß Kaliningrad „in der Deutung unserer Architekten als westlicher Vorposten, als Vorhof der Rußländischen Föderation [erscheint]. Die architektonische Planung der Stadt soll die Macht unseres großen Staates und die russische Gastfreundlichkeit ausdrücken." In Nord-Süd-Richtung plante Tjan den Durchbruch eines gigantischen Prospektes längs durch das alte Zentrum: „Für den Bau der Magistrale werden die zerstörten Stadtviertel abgetragen. Sie wird so breit werden, daß gleichzeitig Dutzende Autos nebeneinander herfahren können." 175 Michail I. Kalinin hatte 1943 geschrieben, es ergebe sich durch die Kriegszerstörungen in den sowjetischen Städten für die Architekten der

173 Naumov, Kakim budet Kaliningrad, in: Kaliningradskaja Pravda, 30. April 1949.

174 Navalichin, K voprosu rekonstrukcii centra goroda Kaliningrada, S. $96 \mathrm{f}$.

175 Tjan, Sovetskij gorod Kaliningrad, in: Kaliningradskaja Pravda, 7. November 1947. 
„historisch seltene Fall, daß architektonische Vorhaben in unvergeßlich großem Maßstab verwirklicht werden" könnten ${ }^{176}$ - diese Chance wollte Tjan nun also in Kaliningrad nutzen. Als Vorbild für den vorgesehenen übertrieben breiten Prospekt diente ihm die Vorzeigestraße der Sowjetunion, die Gorkij-Straße in Moskau, deren Umgestaltung eines der Kernprojekte des "Generalplanes für die Rekonstruktion Moskaus" war177. Während der Errichtung der Gorkij-Straße Ende der 30er Jahre führte die Begeisterung für Straßenerweiterungen dazu, daß die ehemalige Tverskaja Straße breiter wurde, als es nach dem Generalplan von 1935 vorgesehen war: Von ursprünglich 18 Metern wurde sie auf 59 Meter anstatt nur auf 40 Meter verbreitert ${ }^{178}$. Die Nord-Süd-Achse Kaliningrads sollte die Gorkij-Straße in ihrer Breite sogar noch übertreffen: Zeitweise wurde eine Breite von $65 \mathrm{Me}-$ tern ins Auge gefaßt $\mathrm{t}^{179}$.

\section{Erste Schritte zu einer neuen Stadt}

\section{Das provisorische Zentrum}

Trotz der relativ großen Einmütigkeit in der Frage, wo das neue Zentrum Kaliningrads plaziert werden sollte, hatte die Entscheidung, es an der Stelle des alten Stadtkernes zu bauen, für die reale Stadtplanung zunächst keine Bedeutung: Die Diskussion war insofern akademisch, da längst ein vorläufiges Zentrum am Stalingrader Prospekt, der früheren Hufenallee, bestand und nicht abzusehen war, wann Mittel für die Realisierung der hochfliegenden Pläne im alten Stadtzentrum bereitstehen würden. Der Aufbau beschränkte sich in Kaliningrad in den ersten Jahren deshalb auf relativ enggefaßte Zonen, in denen auf noch vorhandene Gebäude und die Infrastruktur aus der Vorkriegszeit zurückgegriffen werden konnte. Wie der Schadensplan zeigt, der von der Verwaltung des Chefarchitekten in der zweiten Hälfte der vierziger Jahre erstellt wurde, war der Zerstörungsgrad in den westlichen Vororten und am alten Zentrum der Verwaltung am Nordbahnhof, wo sich u.a. das Rathaus und das Landgericht befunden hatten, weit geringer als im alten Stadtkern. In diesem westlichen Bereich des alten Königsberg waren die meisten bewohnbaren Häuser zu finden, und viele

176 Kalinin äußerte sich entsprechend in einem offenen Brief vom Oktober 1943 an den Chef des kurz zuvor gegründeten Staatlichen Komitees für architektonische Angelegenheiten beim Rat der Volkskommissare der UdSSR, Arkadij G. Mordvinov. Zitiert nach: Belov, Podnjatie iz ruin, S. 47.

177 Zum Moskauer Generalplan von 1935 vgl. Day, Building Socialism, S. 44-48 und 64-70; Kasus, Die Große Illusion, und Čenyšev, General'nyj plan.

178 Vgl. Day, Building Socialism, S. 65, Anm. 272.

179 Vgl. die Abbildung No. 11,3 in: Navalichin, K voprosu rekonstrukcii centra goroda Kaliningrada. 
Bürogebäude der Vorkriegszeit rund um den Nordbahnhof waren entweder unbeschädigt oder leicht wiederherzustellen. Die Macht von Provisorien läßt sich am Fall Kaliningrad besonders eindrucksvoll nachzeichnen: Noch heute befinden sich die meisten Behörden Kaliningrads in den Gebäuden, die sie in der Nachkriegszeit bezogen ${ }^{180}$.

Wegen der Bedeutung, die sowjetische Planer den Stadtzentren beimaßen, und aufgrund der Ablehnung der deutschen Architektur erschien es jedoch unabdingbar, im Zuge der vorrangigen Bebauung Kaliningrads das provisorische Zentrum gemäß den Regeln des sowjetischen Städtebaus umzugestalten - noch bevor der Generalplan, den Giprogor erarbeitet hatte, vom Ministerrat der RSFSR bestätigt und somit rechtsgültig geworden war ${ }^{181}$. Den Auftrag für die Umgestaltung des Stalingrader Prospektes erteilte wieder die Verwaltung für Architektur beim Ministerrat der RSFSR. Die Oberaufsicht durch das Staatliche Komitee für architektonische Angelegenheiten und die Auftragsvergabe durch die Verwaltung für Architektur führten dazu, daß eine relativ kleine Gruppe von Architekten den Entwürfen ihren Stempel aufdrücken konnten ${ }^{182}$. Dazu kam, daß die Mitglieder des Komitees und seiner Unterabteilungen auf Ebene der Republiken die Wettbewerbe für den Wiederaufbau dominierten und die meisten Expertisen zu den eingereichten Entwürfen aus ihren Reihen kamen. Die Aufgabe des Chefarchitekten einer Stadt war in der Regel darauf beschränkt, die Umsetzung der Planungen sicherzustellen. Um die zentralisierten Entscheidungen nicht zu gefährden, waren die Chefarchitekten jedoch nicht den Stadt- oder Gebietssowjets rechenschaftspflichtig, sondern nur dem Komitee und den entsprechenden Verwaltungen für Architektur ${ }^{183}$. Auch im Kaliningrader Fall hatte die Zustimmung des Exekutivkomitees des Gebietssowjets zu den Plänen nur formalen Charakter: Wesentlich war die positive Begutachtung der Projekte durch die Verwaltung für Architektur und die abschließende Genehmigung durch den Ministerrat der RSFSR.

Der Kaliningrader Chefarchitekt Navalichin erhielt nun die Chance, seine Vorstellungen zu verwirklichen, da er und nicht Giprogor am 14. September 1948 mit der Umgestaltung des Stalingrader Prospektes beauftragt worden war ${ }^{184}$. Diese auf den ersten Blick ungewöhnliche Entscheidung erklärt sich

180 Vgl. die entsprechenden Angaben in: Butovskaja, Kaliningrad. Illjustrirovannyj očerk, und Michailova, Kaliningrad. Spravočnik. Putevoditel'.

181 Die Praxis, Pläne für Stadtzentren auszuarbeiten, bevor die eigentlich grundlegenden Generalpläne ausgearbeitet und verabschiedet worden sind, ist nach Day, Building Socialism, S. 77, in der Sowjetunion der Nachkriegszeit häufiger vorgekommen.

182 Über den gegenscitigen Einfluß der Mitglieder des Komitees: Astaf'eva-Dulgač, O proektach vosstanovlenija gorodov, S. 139-148, bes. S. $139 f$.

183 Um die politische Kontrolle über Architektur und Städtebau zu gewährleisten, wurde die gesamte Spitze des Komitees, die Chefs der Verwaltungen für Architektur der Republiken und 28 Chefarchitekten in das ZK aufgenommen. Vgl. Day, Building Socialism, S. $76 \mathrm{f}$.

184 GAKO, f. 520, op. 1, d. 8, 1. 2f., Befehl No. 418 des Chefs der Verwaltung für Architektur 
daraus, daß der Straße von den zentralen Entscheidungsstellen in Moskau für die Gesamtkonzeption des späteren Kaliningrad nur eine untergeordnete Bedeutung zugemessen wurde - handelte es hier doch vermeintlich nur um ein „provisorisches Zentrum“, wie alle Beteiligten immer wieder betonten $^{185}$.

\section{Ein ambivalentes Projekt}

Ein Jahr nach der Auftragsvergabe und acht Monate, nachdem Giprogor den ersten Entwurf für den Generalplan vorgestellt hatte, legte Navalichin seine Pläne für den Stalingrader Prospekt, die am 28. Oktober 1949 vom Gebietsexekutivkomitee gebilligt worden waren, bei der Verwaltung für Architektur in Moskau vor. Am 3. Dezember 1949 trat das Kollegium der Verwaltung unter Leitung seines Chefs, V. Škvarikov, zusammen, um mit Navalichin, Timochin und den Mitarbeitern von Giprogor, die mit dem Kaliningrader Generalplan beschäftigt waren, das Projekt zu besprechen. Navalichin sah in seinen Plänen vor, den Platz des Sieges am Nordbahnhof (ehemaliger Hansaring) als provisorischen, zentralen Demonstrationsplatz der Stadt zu gestalten, um den herum sich hauptsächlich Verwaltungsgebäude gruppieren sollten. Der westlich an den Platz anschließende Teil des Stalingrader Prospektes sollte kaum umgestaltet werden, entsprach er doch mit seiner breiten, geraden Anlage und seiner zum Teil neoklassizistischen wilhelminischen Bebauung weitgehend den sowjetischen Vorstellungen eines Prospektes. Zentrales Element in diesem Bereich sollte das Theater werden, dessen Wiederaufbau in klassizistischen Formen schon 1947 vom Ministerrat der RSFSR beschlossen worden war ${ }^{186}$. Für die weitere Straßenführung des Stalingrader Prospektes hatte Navalichin zwei Varianten erarbeitet: Die erste Variante basierte auf der damals und noch heute bestehenden Struktur, bei der die Straße in einem Bogen südlich um das Theater herumgeführt wird und erst nach einigen Kurven mehrere hundert Meter weiter wieder gerade in westlicher-Richtung verläuft. Die zweite Variante sah eine Begradigung des Stalingrader Prospektes vor, indem sein östlicher Teil zwischen Platz des Sieges und Theater auf der Nordseite des Theaters geradeaus nach Westen weitergeführt würde. Um diese Variante zu realisieren, hätten jedoch etwa ein halbes Dutzend bewohnbare bzw. wiederaufbaufähige Gebäude abgerissen werden müssen.

Die Entwürfe Navalichins verdeutlichen, daß sein Hauptaugenmerk bei diesem Projekt weniger auf der Lösung der Bedürfnisse der Bevölkerung

beim Ministerrat der RSFSR, V. Škvarikov, an den Chefarchitekten der Stadt Kaliningrad, Dimitrij Navalichin.

185 So zum Beispiel noch 1955: Navalichin, $\mathrm{K}$ voprosu architekturnoj rekonstrukcii goroda Kaliningrada, Bd. 1, S. 168, Anm. 1.

186 Vgl. CChIDNIKO, f. 1, op. 11, d. 85, 1. 34. 
lag, sondern hauptsächlich auf der ästhetisch-propagandistischen Wirkung der Architektur. So betonen die von ihm verfaßten und 1950 vom Gebietsexekutivkomitee gebilligten „Regeln für die Bebauung des Stalingrader Prospektes“ deren politisch-symbolischen Gehalt: Die Architektur der Straße und ihrer Gebäude solle „den Heroismus und das Pathos unserer Epoche, die Freude der freien und glücklichen Arbeit ausdrücken", damit die rekonstruierte Magistrale „ihres ruhmvollen Namens würdig“ sei ${ }^{187}$.

Die Besprechung der Pläne im Kollegium der Verwaltung für Architektur muß am 3. Dezember sehr kurz gewesen sein: Das Protokoll hält nur fest, daß die zwei eingeholten Gutachten zum Projekt Navalichins negativ ausgefallen waren und der Chefarchitekt aufgefordert wurde, seine Entwürfe binnen zwei Wochen zu überarbeiten ${ }^{188}$. Bei der zweiten Besprechung im Kollegium am 23. Dezember 1949, an der seitens der Verwaltung für Architektur unter anderem V. D. Golli als Vorsitzender und die Autoren des Kaliningrader Generalplanes, M. R. Naumov und A. N. Donecko vom Giprogor, als Gäste teilnahmen, erhielt der Kaliningrader Chefarchitekt die Gelegenheit, sein Projekt in einem Vortrag noch einmal vorzustellen. Obwohl seine Pläne von der Verwaltung im Prinzip gebilligt wurden, wies das Kollegium Navalichin an, das Projekt enger mit dem Generalplan abzustimmen und stärker die Kritik der Experten zu berücksichtigen ${ }^{189}$.

So hatte nach Meinung des Experten A. N. Kornouchov der strukturelle Aufbau des Stalingrader Prospektes ,im ganzen in dem vorgestellten Projekt einen richtigen Ausdruck gefunden, indem die einzelnen städtebaulichen und architektonischen Voraussetzungen weiterentwickelt und indem die Defekte in der ursprünglichen Bebauung der Straße umgeändert und verbessert wurden“. Dabei seien vernünftige Versuche gemacht worden, den „vormals für uns fremden Anblick dieser Straße zu ändern, sowohl in Hinsicht auf die geplante Bebauung als auch in Hinsicht auf die Gestaltung der Gebäudefassaden. Diese Aufgabe entstand aus der Notwendigkeit, dem gegebenen Bezirk den Charakter einer sowjetischen Stadt zu verleihen, wo die Sorge um den Menschen eine Bebauung in vernünftiger Dichte, die Regelmäßigkeit des Grundrisses, gerade Straßen, gemütliche, schöne, ordentliche Häuser usw. erfordert." Insgesamt schien ihm die Lösung der Aufgabe jedoch zu wenig durchgreifend. Zwar billigte er dem Kaliningrader Chefarchitekten $z u, d a ß$ „angesichts der architektonischen Widersprüchlichkeit und Buntscheckigkeit [...] die Schaffung eines einheitlichen architektonischen Ensembles überaus schwierig“ sei, doch regte er an, „zwecks eines allergrößten Prunkes [paradnost'] und verkehrsmäßiger Bequemlich-

187 Zitiert nach Lapin, Glavnaja Magistral, in: Kaliningradskaja Pravda, 21. April 1953.

188 GAKO, f. 520, op. 1, d. 8, 1. 5 f., Protokoll No. 58 des Kollegiums der Verwaltung für Architektur beim Ministerrat der RSFSR vom 3. Dezember 1949.

189 GAKO, f. 520, op. 1, d. 8, 1. 20, Protokoll No. 62 des Kollegiums der Verwaltung für Architektur beim Ministerrat der RSFSR vom 23. Dezember 1949. 
keit bei der Verbindung mit dem Platz des Sieges eine kühnere Begradigung" des östlichen Abschnittes des Stalingrader Prospektes durchzuführen.

Das Wort paradnost', das sich nur ungenau mit Prunk übersetzen läßt, da es vom deutschen Wort Parade abgeleitet ist, weist auf die in Kornouchovs Augen wichtigste Aufgabe der Umgestaltung hin: Eingehend beschäftigte sich der Experte mit der räumlichen Gestaltung des Platzes des Sieges, auf dem seit 1945 die zentralen Demonstrationen und Paraden abgehalten wurden. Kornouchov bemängelte insbesondere die geplante Nord-Süd-Ausrichtung des Platzes, die das Einbiegen der Demonstrationszüge von dem in ost-westlicher Richtung verlaufenden Stalingrader Prospekt erschwert hätte. Letztlich orientierte sich seine Bewertung somit vorrangig an der Eignung der geplanten Bebauung, als Kulisse für Massenaufmärsche zu dienen 190 .

Der zweite Experte Ja. A. Kornfel'd, korrespondierendes Mitglied der Akademie für Architektur der UdSSR, äußerte sich zu den Entwürfen sehr viel negativer. Auch er sah das Ausgangsproblem, daß sich die „architektonische Umgestaltung der Bebauung [...] durch ihren chaotischen Charakter, die dünnwandige Bauweise und die unmöglichen Aufbauten" erschwere. Doch bleibe die architektonische Bearbeitung der meisten wiederaufzubauenden Häuser im Projekt „sehr karg“. Im Prinzip könne man alle Ausgangspositionen des Projektes „als von der allgemeinen Richtung her richtig, aber ungenügend" einschätzen. Bei der Mehrzahl der Gebäude des Stalingrader Prospektes sei es vorgesehen, so bemängelte Kornfel'd, „sie in den ursprünglichen Ausmaßen wiederaufzubauen, die unter den Bedingungen des kapitalistischen Eigentums entstanden sind“". Anzustreben sei statt dessen „bei jedem Punkt eine Vereinheitlichung, eine Verdichtung der Bebauung, deren Aufstockung, die Zusammenfassung vereinzelter Häuschen und die Schaffung eines neuen Maßstabes in der Bebauung, die vom sozialistischen Staat verwirklicht wird“. Eindrücklich legte Kornfel'd auf die ideologische Frontstellung Wert, die in der Architektur zum Tragen kommen sollte: Die wiederaufzubauende Magistrale solle ihres ,ruhmvollen Namens würdig sein, und das nicht nur für sowjetische Menschen und ihre Freunde, sondern auch für die Gegner. Sie soll die Verkörperung des organisierenden und verändernden Willens des Sozialismus sein. Dafür ist neben der Sachlichkeit und der wirtschaftlichen Sparsamkeit, die im Projekt zu finden ist,

190 Alle Zitate aus: GAKO, f. 520, op. 1, d. 8, 1. 7-12, Expertise von A. N. Kornouchov zum Schema der vorrangigen Bebauung und zum Projekt der Bebauung des Stalingrader Prospektes vom 10. Dezember 1949. Auch bei der Planung von Stalinstadt (Eisenhüttenstadt) spielten Demonstrationsabläufe eine große Rolle. Die Architekten präsentierten Stadtschemata, auf denen die vorgesehenen Demonstrationszüge, ihre Routen und die für den Weg veranschlagte Zeit eingetragen waren. Zu Eisenhüttenstadt vgl. Beier, Aufbau Ost, Aufbau West, bes. S. 35-50. 
ein schöpferischer Ausdruck notwendig, der nicht eine Minute das allgemeine Ziel und die Richtung der Rekonstruktion aus den Augen verliert." Darum müsse man bei aller Bescheidenheit der Mittel bestrebt sein, den Charakter der gesamten Bebauung entschieden zu ändern und somit „aus ihr den Geist des Preußentums auszumerzen und unsere sowjetische Kultur in der architektonischen Landschaft der Magistrale zu festigen. Insbesondere muß man den finsteren [...] ${ }^{191}$ Geist der preußischen Architektur überwinden und ausrotten - samt deren übermäßig schweren Formen von blickverstellenden Mauern und sperrigen, spitzen Dächern. An seiner Stelle soll die leichte Lebensfreude von Formen treten, die Freundlichkeit des Äußeren und die moderne Architektur, die für unsere sowjetischen Städte charakteristisch ist." In diesem Zusammenhang kritisierte er die geplanten Umbauentwürfe für einige Gebäude, in denen er im Vergleich zum akzeptablen Grundkonzept einen Rückschritt sah. So werde zum Beispiel der Nordbahnhof mit seinen „schweren Portikus-Pfeilern, mit seiner trockenen Kasernen-Geometrie“ nur unentschlossen umgestaltet. Anstelle einer möglichen Auflockerung werde der Bahnhof durch einen „schwerförmigen, zu großen und unmaßstäblichen Turm ergänzt, der architektonisch zusammen mit den Pfeilern und anderen Elementen das auch so schon finstere Bauwerk des Bahnhofes nur noch weiter beschwert. Man kann die Idee, die in diesem Turm liegt, gutheißen, die Idee, daß dieser Turm geistig verwandt sein soll mit den russischen Türmen. Aber es soll kein Festungsturm werden, sondern ein leichter, ziviler, kein kriegerischer Turm. Der Turm soll stufenförmig und durch seine Bearbeitung nach oben hin leichter werden und eine reiche Silhouette erhalten. In diesem Sinne besitzen wir in genügender Anzahl großartige Beispiele. Die in der gegebenen Komposition verwendeten Formen in der Art von grandiosen Akroterien [Erböbungen auf den Giebeln zum Aufstellen von Statuen, Vasen etc., d. Verf.] und schweren Absätzen von fensterlosen Mauern sind nur vereinzelt an der Assoziation des Spasskaja-Turmes [des Moskaner Kremls, d. Verf.] orientiert, durch einige Striche der Silhouette, doch von ihrem Geist her sind sie eklektizistisch und besitzen nicht die wesentlichen Qualitäten - Leichtigkeit und Optimismus der Formen."

Aus all dem folgerte der Moskauer Experte, daß Navalichin und seine Mitarbeiter dem zum Opfer gefallen waren, wogegen der Chefarchitekt doch selbst ankämpfte - dem schädlichen Einfluß der deutschen Architektur. Es entstehe der Eindruck, so schloß Kornfel'd seine Expertise, „daß die Autoren ein wenig Gefangene der alten architektonischen Landschaft der Stadt mit ihrem freudlosen Kolorit" geworden seien. Dieser Einfluß komme „in der Traurigkeit und der Finsternis der Formen zum Ausdruck“, und dies nicht nur beim Nordbahnhof, sondern auch bei den Eingängen zum ge- 
planten Stadion, dem Monument der Kämpfer und dem Umbau der ehemaligen Luisen-Kirche ${ }^{192}$.

Trotz dieses geradezu vernichtenden Urteiles wurde das Projekt in seinen Grundzügen auf der Sitzung vom 3. Dezember mit den erwähnten Auflagen gebilligt. Im fernen Moskau schloß man sich der Auffassung der Experten an, die für eine möglichst durchgreifende Umgestaltung Kaliningrads plädiert hatten, und beauftragte deshalb Navalichin, für den Stalingrader Prospekt den Straßendurchbruch nördlich des Theaters als Grundlage für seine Arbeit zu wählen. Die überarbeitete Variante sollte zum 15. Januar 1950 noch einmal vorgelegt werden ${ }^{193}$. Für diese im Laufe des Jahres 1950 abschließend angenommene Ausarbeitung berücksichtigte der Chefarchitekt Kaliningrads vor allem die Empfehlungen für die Ausrichtung des Platzes des Sieges - ansonsten blieb es weitgehend bei den bereits vorliegenden Entwürfen, die in den folgenden Jahren die Grundlage für den Um- und Wiederaufbau des Stalingrader Prospektes bildeten.

\section{Vorbild Moskau}

\section{Wettstreit der Planer}

In einem Punkt hatten sich die Experten aus Moskau sicherlich geirrt: Navalichins Bereitschaft, das alte Königsberg umzugestalten, ging sehr viel weiter, als sie es in ihren Expertisen vermuteten. Daß der Kaliningrader Chefarchitekt dabei zudem eine bemerkenswerte Durchsetzungsfähigkeit gegenüber den Moskauer Behörden und Zentralinstituten an den Tag legte, zeigt die Auseinandersetzung um die Planung für das alte Stadtzentrum.

Wenige Monate nachdem das Projekt für den Stalingrader Prospekt verabschiedet war und bereits seine Realisierung begann, erging im August 1950 der Auftrag für die Ausarbeitung der „detaillierten Bebauung“ des alten Stadtzentrums ${ }^{194}$. Der Generalplan, der eigentlich das Fundament dieses neuen Projektes bilden sollte, war jedoch noch immer nicht verabschiedet es sollte noch bis zum 16. Mai 1953 dauern, bis der Ministerrat der RSFSR den Generalplan billigte. Für Navalichin war dies offensichtlich kein Manko. Auf einer Versammlung der Kaliningrader Architekten im November 1950 konnte er der Situation sogar positive Züge abgewinnen. „Die

192 Alle Zitate aus: GAKO, f. 520, op. 1, d. 8, 1. 13-16, Expertise von Ja. A. Kornfel'd zum Schema der vorrangigen Bcbauung und zum Projekt der Bebauung des Stalingrader Prospektes vom 2. Dezember 1949.

193 GAKO, f. 520, op. 1, d. 8, 1. 20, Protokoll No. 62 des Kollegiums der Verwaltung für Architektur beim Ministerrat der RSFSR vom 23. Dezember 1949.

194 So die Information laut: GAKO, f. 522, op. 1, d. 25, 1. 6-11, Protokoll der Versammlung der Architekten Kaliningrads vom 14. November 1950 über die Frage des detaillierten Projektes für die vorrangige Bebauung des Stadtzentrums. 
Frage des Fehlens eines bestätigten Generalplanes und des daraus folgenden Stadiums des Projektes der Baufluchtlinien erlaubt es, wahrhaftige Arbeit im Stadium der Projektierungsaufgabe durchzuführen“, erklärte er. Entschlossen, seine Chance zu nutzen, schlug Navalichin vor, schon in den kommenden Monaten mit den Planungen für den "zentralen Bezirk" der Žitomirskaja und Majakovskaja Straße (ehemals Steindamm und Vorstädtische Langgasse, heute beides Lenin-Prospekt) zu beginnen, da dieser Bereich den "Charakter der beiden Straßen und insbesondere den Rayon des zukünftigen Zentrums" bestimme ${ }^{195}$. Bei der Planung des Hauses der Sowjets und dessen unmittelbarer Umgebung wollte er jedoch zunächst noch abwarten, da „zuerst über die allgemeine Komposition entschieden und die Höhe und der Charakter der Bebauung und die Ausmaße des Platzes festgelegt" werden müßten ${ }^{196}$.

Im folgenden Jahrzehnt standen die Entwürfe aus dem Büro des Chefarchitekten der Stadt Kaliningrad fortwährend in Konkurrenz zu den Plänen des Moskauer Giprogor, dessen Einfluß als Zentralinstitut anscheinend rapide abgenommen hatte, seitdem das Staatliche Komitee für architektonische Angelegenheiten Ende 1949 aufgelöst und durch ein Ministerium für Städtebau ersetzt worden war. Da die Aufgaben dieses neuen Ministeriums mehr darin bestanden, sich um quantitative Erfolge beim Wiederaufbau der sowjetischen Städte zu kümmern als um die städtebauliche Gestaltung ${ }^{197}$, vergrößerte sich der Spielraum der lokalen Chefarchitekten auf dem Gebiet der Gestaltung. Bemerkenswerterweise präsentierte Navalichin sowohl sein später von den Experten der Verwaltung für Architektur verrissenes Projekt für den Umbau des Nordbahnhofes als auch sein Projekt des Neuaufbaus des Stadtzentrums in der Öffentlichkeit, bevor diese von den zuständigen Stellen genehmigt worden waren ${ }^{198}$. Die Ausarbeitung der Alternativplanungen für das alte Zentrum zog sich aber trotz seiner Entschlossenheit, die eigenen Ideen durchzusetzen, noch einige Jahre hin. Erst kurz vor der Ver-

195 Tatsächlich legte Navalichin Anfang 1954 erste Entwürfe für die Majakovskaja Straße (heute südlicher Abschnitt des Lenin-Prospektes, ehemals Vorstädtische Langgasse) vor. Vgl. Razrabotka detal'nich proektov central'nich magistralej, in: Kaliningradskaja Pravda, 3. Februar 1954.

196 Alle Zitate aus: GAKO, f. 522, op. 1, d. 25, 1. 6-11, Protokoll der Versammlung der Architekten Kaliningrads vom 14. November 1950 über die Frage des detaillierten Projektes für die vorrangige Bebauung des Stadtzentrums.

197 Tatsächlich wurden im Gründungsdekret des Ministeriums die bisherigen Leitbegriffe der sowjetischen Architektur „Kunst“ und „Schönheit“ gar nicht erwähnt. Vgl: Ukaz Verchovnogo Soveta SSSR. Ob obrazovanij obšesojuznogo Ministerstva gorodskogo stroitel'stva, in: Architektura i stroitel'stva 7 (1949), S. 1, und Day, Building Socialism, S. 86 f.

198 Zum Nordbahnhof siche: Kaliningradskaja Pravda, 23. Oktober 1949; zum Zentrumsentwurf siehe: ebenda, 11. Februar 1953 (das war drei Monate, bevor der Generalplan von Giprogor vom Ministerrat der RSFSR gebilligt wurde, auf den sich Navalichin offiziell als seine Planungsgrundlage beziehen mußte). In beiden Fällen wurde jeweils ein Bildkasten mit Navalichin vor einer Abbildung des entsprechenden Entwurfes abgedruckt. 
abschiedung des von Giprogor ausgearbeiteten offiziellen Generalplanes im Mai 1953 veröffentlichte der Chefarchitekt seine eigenen Arbeiten.

Dieser Generalplan sah wie schon seine erste Fassung von 1949199 vor, das alte Zentrum zwar durchgreifend umzugestalten, doch schon wegen der im Boden erhaltenen Versorgungsleitungen das alte Straßennetz weitgehend beizubehalten. So war nur der Durchbruch von zwei neuen Prospekten vorgesehen, vier andere Hauptverkehrsstraßen sollten lediglich verbreitert werden. Weiterhin war die Errichtung eines Hauses der Sowjets anstelle des Schlosses geplant, an welches sich südlich der zukünftige zentrale Platz der Stadt anschließen sollte. Die Uferzonen und die Pregelinsel (ehemals Kneiphof) sollten komplett geräumt und zu einem städtischen Park umgestaltet werden. Östlich der Insel war in einem weiteren Park ein großes Stadion vorgesehen ${ }^{200}$.

Navalichin nahm die Grundkomponenten dieser Planung (Lage des Hauses der Sowjets, neue Straßendurchbrüche, städtischer Park auf der Pregelinsel, Stadion am Zusammenfluß von altem und neuem Pregel, Auflockerung der Bebauung) zwar auf, radikalisierte seinen Entwurf jedoch wesentlich. Offensichtlich hatte er sich die Kritik der Experten an seinen Plänen für den Stalingrader Prospekt zu Herzen genommen: Den Vorwurf, dem er damals ausgesetzt wurde, er gestalte Kaliningrad nicht entschieden genug zu einer russisch-sowjetischen Stadt um, richtete nunmehr er gegen die Planer aus Moskau. In der Gegenüberstellung seines Projektes mit der Planung von Giprogor warf er den Moskauer Architekten noch 1958 vor, zu zaghaft mit den bestehenden Strukturen umgegangen zu sein. Schon den Ansatz der Planung, die deutsche Bebauung und die alten Versorgungsleitungen so weit wie möglich zu erhalten, um so Geld zu sparen, erklärte er für falsch, da deren praktischer Wert vernachlässigbar sei. Statt dessen führe die „klare Überbewertung der teilweise nach dem Krieg im Zentrumsbereich erhaltenen Wohnbebauung und Versorgungsleitungen“ zu einer „überflüssigen Abhängigkeit des [neuen] Projektes von der ehemaligen Planung“. Mit ihren Entwürfen würden die Architekten von Giprogor deshalb „unfreiwillig einige negative Merkmale der ehemaligen Stadt Königsberg in der sowjetischen Stadt Kaliningrad verstärken" - bei der Neubebauung der Stadt sei es jedoch „besonders wünschenswert“, eben diesen Zuständen zu entfliehen ${ }^{201}$. Diese Mängel trügen die „Merkmale des Konservatismus in sich, die die weitere Entwicklung Kaliningrads als moderne sowjetisch-russische Stadt" störten ${ }^{202}$. Indirekt forderte er, die Innenstadt als tabula rasa zu be-

199 Vgl. Naumov, Kakim budet Kaliningrad, in: Kaliningradskaja Pravda, 30. April 1949.

200 Da zu diesem Generalplan, abgesehen von dem Artikel vom 30. April 1949 über seine erste Fassung, keine Primärquellen aufzufinden waren, beziehe ich mich hier auf die Darstellung von Navalichin in: ders., K voprosu rekonstrukcii centra goroda Kaliningrada, S. $98 \mathrm{f}$.

201 Ebenda, S. 104.

202 Ebenda, S. 101. 
trachten: Insgesamt seien die „Möglichkeiten, die in Zusammenhang mit den bestehenden Zerstörungen der Stadt für die Schaffung eines maximalen Komforts [udobstv] für die Bevölkerung entstanden sind“", viel zu wenig genutzt worden 203 .

Ein besonderes Anliegen war dem Chefarchitekten Kaliningrads schließlich das Haus der Sowjets, dessen Bearbeitung im Generalplan von Giprogor in seinen Augen zu kurz gekommen war. Negativ beurteilte Navalichin vor allem die im Generalplan vorgesehene "mittlere Höhe“ des Hauses der Sowjets: Die Behandlung des „führenden Ensembles“ als „gewöhnliches Gebäude“ ließ es für ihn als Fluchtpunkt von Magistralen völlig ungeeignet erscheinen. Der Generalplan habe weder die Frage nach der „plastischen Verbindung" des Hauses der Sowjets mit anderen städtischen Ensembles noch die „symbolisch-künstlerische Gestalt und die Silhouette“ dieses Gebäudes gelöst. All diese Fragen seien beim Wiederaufbau „einer gewöhnlichen sowjetischen Stadt möglicherweise nicht Aufgabe des Generalplanes, doch unter den gegenwärtigen Verhältnissen von Kaliningrad, wo nicht nur Fragen der Organisation gründlich revidiert werden, sondern auch der symbolische Gehalt und die früher bestehende Form, ist es unabdingbar, darauf eine ausführlichere und inhaltsvollere Antwort gerade in diesem Dokument zu finden" 204.

Die Antwort auf die besondere Situation der annektierten Stadt sah Navalichin also in der konsequenten Veränderung der Stadtlandschaft im Vergleich zu ihrem Vorkriegszustand. Eine paradoxe Lage: Die Planer von Giprogor, die aufgrund der Tatsache, daß sie ihre Projekte am grünen Tisch in der fernen Haupstadt anfertigten, anfälliger schienen für stark ideologisch orientierte Entwürfe, hatten einen eher technokratischen Plan vorgelegt, während der Kaliningrader Chefarchitekt, bei dem aufgrund seiner Nähe zum Planungsgegenstand ein differenziertes Vorgehen erwartet werden könnte, sich durch ein radikaleres Vorgehen profilierte: Sein Ansatz, den er den vergleichsweise moderaten Planungen von Giprogor gegenüberstellte, basierte auf der Idee, Kaliningrad soweit wie möglich zu einem Abbild Moskaus umzuformen.

Eine ähnlich paradoxe Situation war zur gleichen Zeit in Riga zu beobachten: Auch die lettische Akademie der Wissenschaften sah, wie bereits erwähnt, in der Architektur ihrer Hauptstadt das Erbe deutscher Besatzer. Sie plädierte deshalb dafür, deren Altstadt durch Straßendurchbrüche und -erweiterungen, durch neue Plätze und die Errichtung repräsentativer Verwaltungsgebäude grundlegend umzugestalten. Dieses Projekt fand unter den örtlichen Planern anscheinend größeren Rückhalt als in Moskau: Dort kritisierten sogar Mitglieder der Akademie der Architektur der UdSSR und des 
Staatlichen Komitees für Architektur die Pläne als „unwissenschaftlich“ und forderten Modifikationen ${ }^{205}$.

\section{Die Stadt als Siegesdenkmal}

Was in Navalichins Kritik am Generalplan bereits anklang, entwickelte er in dem Entwurf weiter, den er 1954 parallel zur Arbeit von Giprogor gemeinsam mit Architekten des Gebietsplanungsinstitutes (Kaliningradskaja oblastnaja proektnaja kontora - Olproekt) ausgearbeitet hatte 206 . Kernpunkt seines Planes war das Bemühen, für Kaliningrads Zentrum eine "funktionale, symbolische und kompositorische Einheit" herzustellen, wobei Navalichin als Beispiel für eine solche Einheit denkwürdigerweise vor allem Moskauer Siegesmonumente anführte: So zum Beispiel die Grablegungskirche [cerkov rizpoloženija], gebaut 1485 bis 1486 zum Gedächtnis des Sieges von Vasilij dem Dunklen über die Tataren im Jahr 1451, und die Kirche des Seligen Vasili [cerkov Vasili Blažennogo], gebaut 1555 bis 1560 zum Gedächtnis des Sieges von Ivan dem Schrecklichen über die Khanate Kazan und Astrachan. Auch in sowjetischen Städten wie Stalingrad seien „eine Reihe von Plätzen und die sie bildenden Gebäude [...] bestimmten Ereignissen gewidmet: Der Platz der Kämpfer, der Platz der Helden, der Park des Sieges sind dazu berufen, das Heldentum und das Pathos des Großen Vaterländischen Krieges auszudrücken."207 In diese Reihe gestellt, gewinnt die vom Chefarchitekten für Kaliningrad geplante Schaffung eines „ganzen Systems von Ensembles, die reich an symbolischem Gehalt sind“, eine sehr konkrete Aussage. Die möglichst umfassende Umgestaltung der Stadt, die Navalichin „unter den Verhältnissen des Zentrums von Kalingrad“ als „besonders prinzipiell und aktuell“ ansah, da das ehemalige Königsberg keine „tiefen russischen Traditionen“ besäße ${ }^{208}$, zielte darauf ab, die ganze Stadt zu einem bewohnten Siegesdenkmal umzuwandeln.

Schon die Namen, die die Kaliningrader Plätze und Straßen nach 1945 erhalten hatten, waren für Navalichin Programm: „Platz des Sieges“, „LeninProspekt“, „Kalinin-Platz“, „Majakovskij-Prospekt“ - all dies waren für ihn „große Themen für eine breite, schöpferische Entwicklung einer neuen symbolischen Existenz der Stadt" ${ }^{209}$. Diese neue symbolische Existenz der Stadt sollte sich auf zwei Ebenen äußern. Zum einen nahm Navalichin mit dem Hinweis auf die neuen Straßennamen, denen er noch eine „Allee der Helden“ und eine "Allee der Tapferen“ hinzufügen wollte, Bezug auf

$205 \mathrm{Vgl}$. Bogdanov, Voprosy rekonstrukcii, hier: S. 61 und 77.

206 Vgl. Razrabotka detal'nich proektov central'nich magistralej, in: Kaliningradskaja Pravda, 3. Februar 1954.

207 Navalichin, K voprosu rekonstrukcii centra goroda Kaliningrada, S. $162 \mathrm{f}$.

208 Ebenda, S. 164.

209 Ebenda, S. 186. 
Stalingrad. War die Heldenstadt an der Wolga Zeichen der sowjetischen Abwehr und der beginnenden Niederlage der deutschen Invasoren, so war Kaliningrad - schon durch seine bloße Existenz - Symbol des vollendeten Sieges über die Deutschen. Dieser Bezug war bereits in der unmittelbaren Nachkriegszeit aufgestellt worden: Nicht zufälligerweise hieß die Hauptstraße im Westen Kaliningrads „Stalingrader Prospekt“.

Zum anderen plante Navalichin, diesen Sieg durch die Umgestaltung Kaliningrads nach Moskauer Vorbild zu visualisieren - die Hauptstadt der Sieger wurde auf dem annektiertem Territorium in kleinerem Maßstab verdoppelt, um den Anspruch auf dieses Gebiet zu bekräftigen. Die Transformierung der Kaliningrader Stadtlandschaft zu einer verkleinerten Kopie der russischen Hauptstadt war schon ein Thema der Planung für den Stalingrader Prospekt von 1948/49 gewesen. Damals hatte Navalichin einzelne Gebäude durch Kremltürme ergänzen und eine Straßenverbreiterung nach Moskauer Muster vornehmen wollen. Die eigentliche Intention des Chefarchitekten Kaliningrads hatte der Experte Kornfel'd damals jedoch nicht verstanden, wie seine Kritik insbesondere an den Türmen zeigte. Kornfel'd hatte sich in seiner Expertise leichte, „zivile“ Türme gewünscht - genau diese hätten aber der neuen Rolle der Stadt widersprochen. Das ehemalige Königsberg hatte sich von der Aufmarschbasis des deutschen Militarismus zu einem „Vorposten Rußlands“ gewandelt, wie Dimitrij Tjan schon 1947 festgestellt hatte 210 . Die Türme hatten daher eine doppelte Funktion zu erfüllen: Sie versetzten Kaliningrad nicht nur gedanklich von der Küste weit in das Landesinnere, indem sie mit ihrer Architektur die Zugehörigkeit der Stadt zum alten, vorpetrinischen Kern Rußlands propagierten ${ }^{211}$, sondern verwiesen zudem auf die Rolle der Stadt als Abwehrbastion gegen Gefahren aus dem Westen.

In seinem Zentrumsentwurf von 1954 ging Navalichin im Vergleich zu seinen Plänen vom Ende der vierziger Jahren aber noch wesentlich weiter. Nicht nur das Erscheinungsbild einzelner Gebäude und Straßenzüge sollte den Betrachter an die russische Hauptstadt erinnern, sondern der gesamte Stadtgrundriß Kaliningrads sollte dem von Moskau angepaßt werden. Als Grundstruktur beabsichtigte der Chefarchitekt den bestehenden ehemali-

210 Tjan, Sovetskij gorod Kaliningrad, 7. November 1947.

211 Die in Rußland nach dem Zweiten Weltkrieg weitverbreitete Abkehr von westlichen Architekten der Renaissance und des (Neo-)Klassizismus (von Palladio bis Peter Behrens) und der Rückgriff auf vorpetrinische Architektur beim Wiederaufbau russischer Städte wird allgemein als Zeichen für die verordnete Selbstisolierung der Sowjetunion nach Beginn des Kalten Krieges gesehen. Vgl. Ikonnikov, Architektur und Utopie, S. 28-36. Eine vergleichbare Instrumentalisierung von historistischen Baustilen, um eine „wiedergewonnenes Gebiet" geistig an das neue Vaterland zu binden, läßt sich auch in Straßburg nach 1871 feststellen: Um den Anspruch des Deutschen Reiches auf die Stadt zu bekräftigen, wurde gegenüber der Altstadtinsel unweit des Palais Rohan eine Kopie der Marburger St. Elisabethkirche als Neubau der Garnisonskirche gebaut. Vgl. Architekten- und Ingenieurverein für Elsaß-Lothringen, Strassburg und seine Bauten, und Cornelissen, Grenzstadt Straßburg. 
gen Befestigungsring um die Innenstadt zu einer äußeren Ringstraße auszubauen, die durch eine neuzuschaffende innere Ringstraße („DzeržinskijStraße“) ergänzt werden sollte. Die bisherigen, durch das Zentrum laufenden Hauptstraßen wollte er radikal begradigen und durch weitere Radialstraßen ergänzen, die auf das Haus der Sowjets zulaufen sollten, das anstelle des Schlosses vorgesehen war. An den Kreuzungen der äußeren Ringstraße mit den Radialstraßen plante Navalichin eine Reihe von Ensembles, die sich an den gerade vollendeten Moskauer Hochhäusern orientierten ${ }^{212}$.

Besondere Aufmerksamkeit schenkte der Chefarchitekt dem Haus der Sowjets, wie seine Kritik an den entsprechenden Vorschlägen Giprogors bereits verdeutlichte. Alle anderen Ensembles der Stadt hatten sich diesem Palast unterzuordnen: „Sie müssen mit allen zur Verfügung stehenden Mitteln der Architektur, der Farbe usw. sein symbolisches, plastisches und künstlerisches Wesen unterstreichen, verdeutlichen und kompositorisch vorbereiten [...]. “213 Im ehemaligen Königsberg habe diese Bedeutungshierarchie der Gebäude nicht bestanden: Der Glockenturm des Schlosses sei trotz seiner Höhe von 95 Metern oft nicht gut sichtbar gewesen, da er ,in vielen Fällen von Bauwerken wie Warenhäusern oder der Universitätskirche verdeckt wurde". Die Abstufung der Ensembles und der Durchbruch neuer Magistralen aber schaffe „die Möglichkeit, das Gebäude in seiner Gänze schon aus einer Entfernung von 800 bis 1000 Metern wahrzunehmen"214. Mit architektonischen Mitteln sollte das Haus der Sowjets somit nicht nur, wie Navalichin schrieb, „die dem sowjetischen Menschen nahe und verständliche Idee des Friedens und der friedlichen, heldenhaften Arbeit"215 versinnbildlichen - das „beherrschende Element der ganzen Komposition der Stadt" 216 sollte auch die beherrschende Rolle der Partei im allgemeinen und im ehemaligen Königsberg im besonderen vor Augen führen ${ }^{217}$.

Das prinzipielle Vorbild Navalichins für ein solches zentrales Hochhaus war der Palast der Sowjets in Moskau; als konkretes Vorbild schwebte ihm hingegen das neue Gebäude der Moskauer Lomonosov-Universität vor, die nach den Plänen von Lev Rudnev in den Jahren 1947-1949 südwestlich

212 Vgl. Navalichin, K voprosu rekonstrukcii centra Kaliningrada, S. 175 f. und 183-185; Kasus, Die große Illusion. Zu der Moskauer Hochhausplanung vgl. Oltarševskij, Stroitel'stvo vysotnich zdanii; Schlögel, Moskau - offene Stadt, S. 44-59; und Noever, Tyrannei des Schönen, S. 92-108.

213 Navalichin, K voprosu rekonstrukcii centra Kaliningrada, S. 186.

214 Ebenda, S. 179.

215 Ebenda, S. 182.

216 Ebenda, S. 183.

217 Schon 1938 hatte sich G. Nedošijvijn in dem Artikel „Monunmental'noe isskustvo v strane socialisma" über das Verhältnis der Bauten einer Stadt zueinander geäußert und gefordert, daß ,jedes Brückengeländer ein Glied in der Kette des organischen Ganzen sein“ solle. Er spielte damit auf das gesellschaftliche Leitbild der Epoche an, nach der jeder sowjetische Mensch als organischer Teil des Staates angesehen wurde. (Tvorčestvo 11 (1938), S. 22, zitiert nach: Bown, Kunst unter Stalin, S. $86 \mathrm{f}$.) 
vom alten Moskauer Zentrum gebaut worden war. Eine Skizze und ein Modell der Zentrumsplanungen zeigen das Haus der Sowjets als eine verkleinerte Kopie dieses Universitätsgebäudes. Die optische Übereinstimmung ist jedoch lediglich der Ausdruck für die weitergehende intellektuelle Vorbildfunktion des Architekten der Moskauer Staatlichen Lomonosov-Universität, der bis Mitte der fünfziger Jahre einer der führenden Baumeister der Sowjetunion war. Schon 1944 hatte dieser in einer Expertise für den Wiederaufbau von Voronež empfohlen, das Zentrum der Stadt auf ein „optisch vereinigendes" Hochhaus auszurichten. Er empfahl, alle Innenstädte nach den Prinzipien des Generalplanes für Moskau von 1935 umzugestalten, das heißt streng hierarchisch und symmetrisch auf ein zentrales Verwaltungsgebäude bezogen. 1947 hatte Rudnev sich erfolgreich in die Diskussion über den Wiederaufbau der Stalingrader Innenstadt eingemischt: Mit seinem Entwurf, den er beim Wettbewerb für das Stalingrader Haus der Sowjets einreichte, kritisierte er die im damals anerkannten Wiederaufbauprojekt von Karo Alabjan vorgesehene Grundform des Hauses der Sowjets als politisch nicht korrekt. Alabjan habe das Symbol der Sowjetmacht gleich zweifach in seiner Bedeutung herabgesetzt - zum einen durch seine nur mittlere Höhe und zum anderen durch seine Plazierung an einer Längsseite des Hauptplatzes, statt an der prominenteren Querseite 218 . Der durchschlagende Erfolg dieser Kritik - Rudnevs Hochhausentwurf für das Haus der Sowjets in Stalingrad gewann den ersten Preis, und Rudnev selbst wurde an der Überarbeitung des Zentrumsprojektes beteiligt - mag Navalichin einige Jahre später zur Nachahmung dieser Vorgehensweise animiert haben, indem er Giprogor mit ähnlichen Argumenten attackierte.

Kaliningrad war, wie die Beispiele Voronež oder Stalingrad zeigen, sicherlich nicht die einzige Stadt, die nach Moskauer Vorbild umgestaltet werden sollte $^{219}$, doch es wird wohl kaum eine sowjetische Stadt geben, in der dieses Konzept trotz aller Einschränkungen durch die wirtschaftliche Lage so dogmatisch verfolgt und teilweise auch umgesetzt wurde. Im Stadtbild sind die Bemühungen des Kaliningrader Chefarchitekten, seine Stadt zum zweiten Moskau umzugestalten, heute kaum nachzuvollziehen; erst ein Vergleich des aktuellen Stadtplanes mit den Projekten von Giprogor und Navalichin bringt Erstaunliches zutage: Die wenigen Gebäude, die im Zentrum Kaliningrads bis Anfang der sechziger Jahre errichtet wurden, folgen den Baufluchtlinien der nie offiziell abgesegneten Pläne Navalichins, nicht aber denen des vom Ministerrat der RSFSR gebilligten Generalplans von Giprogor. Am deutlichsten ist dies am oberen Abschnitt des Lenin-Prospektes (ehemals Steindamm, dann bis 1961 Žitomirskajastraße) zu erken-

218 Vgl. Rudnev, Dom Sovetov v Stalingrade, S. 9-14, dazu: Day, Building Socialism, S. $81 \mathrm{f}$.

219 Über die Ausstrahlung der Moskauer Planung nach dem Zweiten Weltkrieg vgl. Kasus, Der Wiederaufbaus Moskaus; und Oltarševskij, Stroitel'stvo vysotnich zdanii. 
nen, der von Navalichin als einer der Prospekte gedacht war, die auf das Haus der Sowjets zulaufen 220 . Offensichtlich setzte sich Navalichin als Chefarchitekt von Kaliningrad einfach über geltende Verordnungen zum Generalplan hinweg bzw. nutzte den Schwebezustand vor deren endgültiger Verabschiedung zu seinen Gunsten aus, wie er es bereits auf der Versammlung der Kaliningrader Architekten im November 1950 angedeutet hatte 221 .

Andererseits mußte auch Navalichin mit seinen Vorstellungen stark zurückstecken. Als er im Sommer 1954 nach der Formulierung seiner Zentrumkonzeption die ersten Häuser für den späteren Lenin-Prospekt plante, hatte er prachtvolle Wohnpaläste vor Augen. In einer Projektbeschreibung des Eckhauses Lenin-Prospekt/Innere Ringstraße (Dzeržinskij-Straße) war für diese zukünftig städtebaulich herausragende Stelle ein fünfstöckiges Haus vorgesehen - die "qualitätvolle Fassade“ sollte möglichst mit Keramikplatten verkleidet und der Laden im Erdgeschoß mit verspiegelten Vitrinen, Mosaiken und edlen Hölzern ausgestattet werden 222. Das tatsächlich gebaute vierstöckige Haus wurde erst fünf Jahre später als schlichtes Typenprojekt in Großblockbauweise errichtet. Die auf dem Leninprospekt realisierten Läden entbehren jeglichen Schmuckes. Als einziges repräsentatives Gebäude wurde das ehemalige, von Oskar Kaufmann errichtete „Neue Schauspielhaus" in Anlehnung an das Moskauer Bolschoj-Theater wiederaufgebaut. Als der Bau nach vierzehnjähriger Planungs- und Bauzeit 1960 endlich eingeweiht wurde, war es mit seinem monumentalen Portikus jedoch bereits Zeugnis einer seit Jahren abgeschlossenen Ära ${ }^{223}$.

Ein weiteres ehrgeiziges Projekt nach Moskauer Vorbild wurde in einer Minimalversion ausgeführt: Neben dem ehemaligen „Park Luisenwahl“, dessen Umgestaltung in den „Kalinin-Kultur- und Erholungspark“ sich in der ersten Hälfte der 50er Jahre schließlich auf das Aufstellen einiger Betonskulpturen spielender Kinder beschränkte, entstand 1954-1955 eine kleine „Ausstellung der Errungenschaften der Landwirtschaft des Kaliningrader

220 Weil das Haus der Sowjets später weiter östlich gebaut wurde, als von ihm vorgesehen war, läuft der Lenin-Prospekt an dieser Stelle ins Leere. Von der inneren Ringstraße ist nur eine große Kreuzung übriggeblieben, die sich nach Süden in eine schmale Gasse fortsetzt und in ihrem nördlichen Teil zu ciner Fußgängerpromenade umgestaltet wurde.

221 Daß geltende (General-)Pläne häufig das Papier nicht wert waren, auf dem sie gezeichnet warcn, mußte Navalichin jedoch selbst erfahren, wie im nächsten Abschnitt zu zeigen ist.

222 GAKO, f. 522, op. 1, d. 92, 1. 18f., Projekt für einen Ncubau an der Žitomirskaja Straße vom 16. 8. 1954.

Als Vorbild dürften hier die Bauten der Stalinallee in Ost-Berlin gedient haben, von deren Neubauten auch die Kaliningradskaja Pravda in dieser Zeit mehrmals Fotos abdruckte.

223 Vgl. GAKO, f. 135, op. 1, d. 5, 1. 7-9, Protokoll vom 4. Juli 1951 der Versammlung der Mitglieder der Kaliningrader Abteilung der Union der Architekten der Sowjetunion, der Kaliningrader Abteilung der Union der Künstler der Sowjetunion und des Direktors des Kaliningrader Dramatischen Theaters über das Projekt des Wiederaufbaus der Kaliningrader Theaters. 
Gebietes“ mit fünf Ausstellungspavillons. Sie orientierte sich an der im Norden der sowjetischen Hauptstadt gelegenen monumentalen „Ausstellung der Errungenschaften der Landwirtschaft der UdSSR“ (später: „Ausstellung der Errungenschaften der Volkswirtschaft der UdSSR“). Das Moskauer Konzept einer weitläufigen Parklandschaft mit breiten Achsen, auf der die Werktätigen von einem Pavillon zum andern schlendern konnten, um sich über die Fortschritte bei der Schafzucht und der Getreideernte oder die neueste Melktechnik zu informieren, ging freilich bei den beengten Kaliningrader Verhältnissen und den beschränkten Mitteln, die hier für den Bau zur Verfügung standen, nicht auf: Zwar sind selbst Details wie die Gestaltung des Einganges als Triumphbogen und des zentralen Ausstellungsgebäudes mit seiner altrussischen Spitze getreu kopiert worden, doch verkümmerte das hauptstädtische Pathos, das vor allem den „neuen Menschen" feiern wollte, in der Kaliningrader Provinz zu einer unfreiwillig komischen Karikatur ${ }^{224}$.

224 Vgl. GAKO, f. 522, op. 1, d. 92, 1. 74-81, Projekt für dic Umgestaltung des Zentralen Kalinin-Kultur- und Erholungsparks und der Ausstellung der Errungenschaften der Landwirtschaft des Kaliningrader Gebietes. Zur Eröffnung erschienen am 28. und 29. Oktober 1955 in der Kaliningradskaja Pravda ausführliche Artikel, in denen die Anlage beschrieben wurde. Zur Moskauer Ausstellung vgl. Schlögel, Moskau - offene Stadt, S. 132-137. 